\title{
Motoneuronal TASK Channels Contribute to Immobilizing Effects of Inhalational General Anesthetics
}

\author{
Roman M. Lazarenko, ${ }^{1}$ Sarah C. Willcox, ${ }^{1}$ Shaofang Shu, ${ }^{1}$ Allison P. Berg, ${ }^{1}$ Vesna Jevtovic-Todorovic,, 3 \\ Edmund M. Talley, ${ }^{1}$ Xiangdong Chen, ${ }^{1}$ and Douglas A. Bayliss ${ }^{1,3}$ \\ Departments of ${ }^{1}$ Pharmacology, ${ }^{2}$ Neuroscience, and ${ }^{3}$ Anesthesiology, University of Virginia, Charlottesville, Virginia 22908
}

General anesthetics cause sedation, hypnosis, and immobilization via CNS mechanisms that remain incompletely understood; contributions of particular anesthetic targets in specific neural pathways remain largely unexplored. Among potential molecular targets for mediating anesthetic actions, members of the TASK subgroup [TASK-1 (K2P3.1) and TASK-3 (K2P9.1)] of background $\mathrm{K}^{+}$channels are appealing candidates since they are expressed in CNS sites relevant to anesthetic actions and activated by clinically relevant concentrations of inhaled anesthetics. Here, we used global and conditional TASK channel single and double subunit knock-out mice to demonstrate definitively that TASK channels account for motoneuronal, anesthetic-activated $\mathrm{K}^{+}$currents and to test their contributions to sedative, hypnotic, and immobilizing anesthetic actions. In motoneurons from all knock-out mice lines, TASK-like currents were reduced and cells were less sensitive to hyperpolarizing effects of halothane and isoflurane. In an immobilization assay, higher concentrations of both halothane and isoflurane were required to render TASK knock-out animals unresponsive to a tail pinch; in assays of sedation (loss of movement) and hypnosis (loss-of-righting reflex), TASK knock-out mice showed a modest decrease in sensitivity, and only for halothane. In conditional knock-out mice, with TASK channel deletion restricted to cholinergic neurons, immobilizing actions of the inhaled anesthetics and sedative effects of halothane were reduced to the same extent as in global knock-out lines. These data indicate that TASK channels in cholinergic neurons are molecular substrates for select actions of inhaled anesthetics; for immobilization, which is spinally mediated, these data implicate motoneurons as the likely neuronal substrates.

\section{Introduction}

The neural mechanisms that mediate important clinical actions of general anesthetics remain uncertain. A prevailing view holds that contributions of individual molecular or neuronal targets depend on the particular anesthetic compound and the specific clinical endpoint examined (for review, see Rudolph and Antkowiak, 2004; Grasshoff et al., 2005; Franks, 2008). This idea follows from the identification of multiple candidate molecular targets for different anesthetic compounds and the realization that various actions (e.g., immobilization vs sedation/hypnosis) engage different brain structures (e.g., spinal vs supraspinal). It implies that understanding the actions of any anesthetic drug demands information on how specific targets within defined neural systems can contribute to each clinically relevant outcome.

The recent availability of genetically modified mice in which candidate anesthetic targets have been disrupted has begun to provide crucial evidence linking drug effects measured on a can-

\footnotetext{
Received March 31, 2010; revised April 20, 2010; accepted April 24, 2010.

This work was supported by American Heart Association Beginning Grant in-Aid 0665349U to X.C. and National Institute of General Medical Sciences Grant GM-66181 to D.A.B. We thank Kat Hopper and Dr. Tekuila Birdsong for help with preliminary behavioral assays and Neil Sen for histochemical assessment of various lines of conditional TASK knock-out mice.

Correspondence should be addressed to Douglas A. Bayliss, Department of Pharmacology, University of Virginia Health System, P.0. Box 800735, 1300 Jefferson Park Avenue, Charlottesville, VA 22908-0735. E-mail: dab3y@ virginia.edu.

DOI:10.1523/JNEUROSCI.1655-10.2010

Copyright $\odot 2010$ the authors $\quad 0270-6474 / 10 / 307691-14 \$ 15.00 / 0$
}

didate channel in vitro to behavioral actions of the anesthetic in vivo. For example, immobilizing and hypnotic actions of intravenous anesthetics were attributed to $\beta_{3}$-containing $\mathrm{GABA}_{\mathrm{A}}$ receptors and sedative effects to $\beta_{2}$-containing receptors (Jurd et al., 2003; Reynolds et al., 2003) based on examination of mice expressing anesthetic-insensitive $\mathrm{GABA}_{\mathrm{A}}$ receptor $\beta$ subunits. In addition, the identification of anesthetic-activated, neuronal background $\mathrm{K}^{+}$currents (Nicoll and Madison, 1982; Franks and Lieb, 1988) and their subsequent association with specific K2P subunits (Patel et al., 1999) has stimulated production and testing of mice with deletions of the cognate channel genes. A role for TREK-1 (K2P2.1) was supported by diminished sensitivity of global knock-out mice to immobilizing and hypnotic effects of various inhalational anesthetics (Heurteaux et al., 2004). Likewise, in mice deleted for either TASK-1 or TASK-3, immobilization required significantly higher concentrations of halothane (but not isoflurane), whereas a shift in hypnotic sensitivity was reported only for isoflurane in TASK $-1^{-1-}$ mice and for halothane in TASK-3 ${ }^{-1-}$ mice (Linden et al., 2006, 2007; Pang et al., 2009). The reason for agent-specific differences in anesthetic sensitivity observed in global TASK knock-out mice is not immediately apparent, and the consequences of deleting both TASK channel subunits simultaneously was not examined. Moreover, because experiments were performed in mouse models in which channel function was disrupted in all cells, differences in behavioral sensitivity could not be assigned to anesthetic modulation of the channels in any particular group of neurons. In fact, a direct demonstration that TASK channels mediate anesthetic-activated 
currents in any specific neuronal population implicated in these anesthetic actions is currently lacking.

In this work, we used single and double TASK subunit knockout mice to demonstrate directly that TASK-1 and/or TASK-3 subunits account for anesthetic-activated background $\mathrm{K}^{+}$currents in motoneurons (Sirois et al., 2000). We further demonstrate that TASK channels are required for normal sensitivity to immobilizing effects of halothane and isoflurane and to sedative/ hypnotic effects of halothane. Importantly, effects of TASK channel deletion on anesthetic-induced immobilization and halothaneevoked sedation were fully recapitulated when TASK channels were ablated selectively in cholinergic neurons. Thus, TASK channel expression in cholinergic neurons, perhaps those in pontine or forebrain nuclei (Talley et al., 2001; Karschin et al., 2001), appears to be necessary for normal halothane-induced sedation. For anesthetic-induced immobilization, which is mediated spinally and associated with decreased motoneuronal excitability (Kendig, 1993; Zhou et al., 1997; 1998; Rudolph and Antkowiak, 2004), somatic motoneurons represent the most likely relevant cholinergic cell type.

\section{Materials and Methods}

All animal use was in accordance with guidelines approved by the University of Virginia Animal Care and Use Committee (Charlottesville, VA); experiments were performed on genetically modified male and female mice.

TASK channel knock-out mice. The derivation of global TASK-1 and TASK-3 knock-out mice has been described previously (Mulkey et al., 2007; Davies et al., 2008), and selective phenotypic characterization of these and other TASK knock-out lines has been presented (Linden et al., 2006, 2007, 2008; Meuth et al., 2006; Mulkey et al., 2007; Davies et al., 2008; Pang et al., 2009). For the current work, individual mouse lines with "floxed" alleles for TASK-1 (TASK-1 ${ }^{\mathrm{f} / \mathrm{f}}$ ) and TASK-3 (TASK-3 ${ }^{\mathrm{f} / \mathrm{f}}$ ) were moved onto a C57BL/6J background by using "speed congenics" (University of Virginia Transgenic Core); subsequently, the floxed exon 2 of each gene was excised by crossing with a Cre-deleter strain, also on a C57BL/6J background (EIIa-Cre; Jackson Laboratories stock \#003724), and the resulting knock-out lines were intercrossed to generate a double TASK- $1^{-1-}$ :TASK- $3^{-1-}$ line $\left(\right.$ TASK $^{-1-}$ ). All knock-out lines were maintained as homozygotes, with the parental C57BL/6J mouse line used as a control strain.

To achieve cell-specific deletion of TASK channels with an emphasis on motoneurons, we obtained multiple mouse lines in which Cre recombinase is expressed in motoneurons and a limited number of other cell populations. These Cre-expressing lines were crossed with our congenic TASK- $1^{\mathrm{f} / \mathrm{f}}$ : TASK- $3^{\mathrm{f} / \mathrm{f}}$ double-floxed lines. For the conditional TASK channel knock-out studies reported here, we used mice in which an internal ribosome entry site (IRES)-Cre cassette was knocked into the choline acetyltransferase locus (ChAT-Cre; The Jackson Laboratory, stock \#006410); in this line, Cre expression is directed selectively to cholinergic neurons, including motoneurons. For various reasons (see below), other mouse lines that were expected to support selective Cremediated recombination in motoneurons were not effective for our purposes; these included another ChAT-Cre line (GENSAT, GM53) (Gong et al., 2007), Isl1-Cre (Srinivas et al., 2001) (received from Dr. J.-P. Liu, University of Virginia), Olig1-Cre, and Olig2-Cre (Lu et al., 2002) [received from Dr. C. D. Stiles (Harvard University, Cambridge, MA) and D. H. Rowitch (University of California, San Francisco, CA)].

For all global and conditional knock-out lines, a multiplex PCR was performed with tail DNA to verify the presence of floxed or deleted TASK channel alleles (TASK-1 primers: GAAGCCCCTGCAGGCAAC, GCTCAGGCTGGGGCTTTTG, GGTCTGACTCTGCTTGGC; TASK-3 primers: GACCTAACTCCTCTCTTCTTCC, CAACACACCTGCACACAGAAG, GCACCCCAAAATGCTTCAGC). To identify Cre-expressing mice, a separate PCR was performed using primers targeting the Cre coding region (GCACGTTCACCGGCATCAAC, CGATGCAACGAGTGATGAGGTTC).
In situ hybridization histochemistry. Nonisotopic in situ hybridization was performed using digoxigenin-labeled cRNA probes, essentially as described previously (Berg and Bayliss, 2007). In brief, mice were perfused transcardially with $4 \%$ paraformaldehyde and brain sections (30 $\mu \mathrm{m})$ were cut on a vibratome, rinsed in sterile PBS, and placed free floating into prehybridization mixture $(0.6 \mathrm{M} \mathrm{NaCl}, 0.1 \mathrm{M}$ Tris-Cl, $\mathrm{pH} 7.5$, $0.002 \mathrm{~m}$ EDTA, $0.05 \%$ sodium pyrophosphate, $0.5 \mathrm{mg} / \mathrm{ml}$ yeast total RNA, $0.05 \mathrm{mg} / \mathrm{ml}$ yeast tRNA, $1 \times$ Denhardt's BSA, $50 \%$ formamide, $10 \%$ dextran sulfate, $0.05 \mathrm{mg} / \mathrm{ml}$ oligo(dA), $10 \mu \mathrm{M}$ four deoxynucleoside triphosphates, $0.5 \mathrm{mg} / \mathrm{ml}$ herring sperm DNA, and $10 \mathrm{~mm}$ DTT) at room temperature for $30 \mathrm{~min}$ and then at $37^{\circ} \mathrm{C}$ for $1 \mathrm{~h}$. Mouse TASK- 1 and TASK-3 (in pcDNA3) were linearized with Spe1 and Stu1, respectively, to yield templates that encompass only the second (i.e., the deleted) exon of each gene (Mulkey et al., 2007; Davies et al., 2008). In vitro transcription was performed on linearized templates using digoxigenin-11-UTP (Boehringer Mannheim); digoxigenin-labeled riboprobes were purified on ProbeQuant G-50 Microcolumns (GE Healthcare) and added to the prehybridization solution. Sections were incubated at $55-60^{\circ} \mathrm{C}$ for $16-20 \mathrm{~h}$, rinsed through decreasing concentrations of salt solutions, treated with RNase A at $37^{\circ} \mathrm{C}$, and then subjected to a final highstringency wash $\left(0.1 \times \mathrm{SSC}\right.$ at $55^{\circ} \mathrm{C}$ for $60 \mathrm{~min} ; 1 \times \mathrm{SSC}: 150 \mathrm{~mm} \mathrm{NaCl}$ and $15 \mathrm{~mm}$ sodium citrate, $\mathrm{pH} 7$ ). Sections were incubated with alkaline phosphatase-conjugated sheep anti-digoxigenin antibody (1:1000; Boehringer Mannheim), and the alkaline phosphatase was reacted with nitroblue tetrazolium and 5-bromo-4-chloro-3-indolyl-phosphate, 4-toluidine salt in colorization buffer ( $50 \mathrm{~mm} \mathrm{MgCl}, 100 \mathrm{~mm}$ Tris, $\mathrm{pH}$ $9.5,100 \mathrm{~mm} \mathrm{NaCl}$ ) while protected from light. The reaction was quenched by rinsing in TE buffer (10 mM Tris, 1 mm EDTA, $\mathrm{pH} 8.5$ ); the sections were mounted onto gelatin-subbed slides and coverslipped, and images were obtained on a Zeiss Axioskop 2 using a PixelFly camera and IPLab software.

ChAT and TASK-3 double-labeling immunohistochemistry. Perfusionfixed brain sections $(30 \mu \mathrm{m})$ were obtained as described above and washed extensively in PBS and $100 \mathrm{~mm}$ Tris-buffered saline (TS) solutions, blocked for $1 \mathrm{~h}$ in $10 \%$ horse serum/0.1\% Triton X-100/TS, and then incubated overnight at $4^{\circ} \mathrm{C}$ with goat anti-ChAT (1:1000; Millipore Bioscience Research Reagents) and rabbit anti-TASK-3 (1:1000) (Berg et al., 2004; Berg and Bayliss, 2007). For detection, sections were incubated $(1 \mathrm{~h})$ with Cy3-conjugated donkey anti-goat antisera (1:1000; Jackson ImmunoResearch Laboratories ) and Alexa Fluor 488-conjugated donkey anti-rabbit antisera (1:2000; Invitrogen). Sections were mounted onto gelatin-subbed slides and coverslipped and images were obtained on a Zeiss Axioskop 2 epifluorescent microscope with appropriate filter sets using a PixelFly camera and IPLab software.

Brain slices. The preparation of brain slices has been described in detail previously (Sirois et al., 1998, 2000). Briefly, neonatal mouse pups of either sex (6-12 d postnatal) were deeply anesthetized (ketamine/xylazine: $200 / 14 \mathrm{mg} / \mathrm{kg}$, i.m.) and decapitated, and transverse brainstem slices were prepared $(300 \mu \mathrm{m})$ using a microslicer (DSK 1500E, Dosaka) in ice-cold sucrose (260 mM)-substituted Ringer's solution (Aghajanian and Rasmussen, 1989) containing kynurenate (1 mM). Slices were incubated for $30 \mathrm{~min}$ at $37^{\circ} \mathrm{C}$ and then at room temperature in normal Ringer's solution containing the following (in $\mathrm{mM}$ ): $130 \mathrm{NaCl}, 3 \mathrm{KCl}, 2 \mathrm{MgCl}_{2}, 2 \mathrm{CaCl}_{2}, 1.25 \mathrm{NaH}_{2} \mathrm{PO}_{4}, 26 \mathrm{NaHCO}_{3}$, and 10 glucose; both substituted and normal Ringer's solutions were bubbled with $95 \% \mathrm{O}_{2} / 5 \% \mathrm{CO}_{2}$.

Electrophysiology. For electrophysiological recording of motoneurons, mouse brainstem slices were transferred to a chamber on the stage of a Zeiss Axioskop and visualized with infrared differential interference contrast optics; hypoglossal motoneurons were identified by their anatomic location and their characteristic size and shape. All recordings were performed at room temperature in HEPES-based bath solutions containing the following (in mM): $140 \mathrm{NaCl}, 3 \mathrm{KCl}, 10 \mathrm{HEPES}, 2 \mathrm{CaCl}_{2}, 2 \mathrm{MgCl}_{2}$, and 10 glucose. Recording pipettes were pulled from borosilicate glass capillaries to a DC resistance ranging from 3 to $5 \mathrm{M} \Omega$ and coated with Sylgard 184 (Dow Corning). For voltage-clamp recordings of TASK-like currents, pipette solution contained the following (in mM): $120 \mathrm{KCH}_{3} \mathrm{SO}_{3}, 4$ $\mathrm{NaCl}, 1 \mathrm{MgCl}_{2}, 0.5 \mathrm{CaCl}_{2}$, 10 HEPES, 10 EGTA, $3 \mathrm{MgATP}, 0.3 \mathrm{GTP}$-Tris, pH 7.2; we also included $50 \mu \mathrm{M}$ ZD7288 (Tocris Cookson) to block pH- 
and anesthetic-sensitive $I_{\mathrm{h}}$ in motoneurons. For current-clamp recordings, pipette solutions contained the following (in $\mathrm{mM}$ ): $17.5 \mathrm{KCl}, 122.5$ potassium gluconate, $10 \mathrm{HEPES}, 0.2 \mathrm{EGTA}, 9 \mathrm{NaCl}, 1 \mathrm{MgCl}_{2}, 3 \mathrm{MgATP}$, 3, 0.3 GTP-Tris, $\mathrm{pH}$ 7.2. We routinely added $0.5 \mu \mathrm{M}$ tetrodotoxin (TTX; Alomone Labs) to the bath solution to block action potentials and, where noted, a bicuculline/strychnine mixture (at 10 and $30 \mu \mathrm{M}$; Sigma) was added to block $\mathrm{GABA}_{\mathrm{A}}$ and glycine receptor channels. Halothane and isoflurane were bubbled into bath solutions through calibrated vaporizers (Ohmeda, GE Healthcare); aqueous concentrations were determined by gas chromatography from samples collected at the point of solution entry into the recording chamber (Sirois et al., 1998; 2000).

Data acquisition and analysis. Voltage commands were applied and currents recorded using pCLAMP software interfaced with an Axopatch 200B amplifier via a Digidata 1322A digitizer (all from Molecular Devices). Series resistance was compensated by $60-75 \%$ and continuously monitored to ensure stability of recordings and adequate compensation. Resting membrane potential was determined directly under current clamp or calculated from the zero current potential under voltage clamp. For voltage-clamp recordings, cells were held at $-60 \mathrm{mV}$ and a series of hyperpolarizing voltage steps $(\Delta-10 \mathrm{mV}$, to $-130 \mathrm{mV})$ or a hyperpolarizing ramp voltage was applied $(0.2 \mathrm{~V} / \mathrm{s}$, from $-60 \mathrm{mV}$ to $-130 \mathrm{mV})$; input conductance was determined from linear analysis of the resultant current-voltage $(I-V)$ relationships around the resting membrane potential $(-60 \mathrm{mV}$ to $-90 \mathrm{mV})$. The characteristics of $\mathrm{pH}$ - and anestheticsensitive currents were obtained by digital subtraction of $I-V$ curves in alkalized and acidified baths and in the presence and absence of inhaled anesthetics; $I-V$ curves were fitted with the Goldman-Hodgkin-Katz (GHK) current equation of the following form:

$$
I=k \frac{z^{2} F^{2}}{R T} V\left(\frac{[\mathrm{K}]_{\mathrm{i}}-[\mathrm{K}]_{\mathrm{o}} e^{\frac{-z V F}{R T}}}{1-e^{\frac{-z V F}{R T}}}\right),
$$

where $I, V, z, F, R, T,[\mathrm{~K}]_{\mathrm{i}}$, and $[\mathrm{K}]_{\mathrm{o}}$ have their usual meanings, and $k$ is a scaling parameter that was fitted by using the Solver function of Excel.

Analysis of anesthetic action in mice. Mice were tested for sensitivity to hypnotic effects of halothane and isoflurane by using the loss-of-righting reflex (LORR) assay. Mice were placed in a sealed plastic container through which a constant flow of anesthetic:oxygen gas mixture was delivered via a calibrated vaporizer and oxygen flow meter; anesthetic concentration in the chamber was continuously monitored using a calibrated infrared analyzer (CapnoMac, Datex, GE Healthcare). After an extensive equilibration period at each anesthetic concentration (halothane: $40 \mathrm{~min}$; isoflurane: $30 \mathrm{~min}$ ), mice were tested for their ability to maintain upright posture (Quinlan et al., 1998). Immobilization was assessed by using a MAC assay, where MAC is the minimum alveolar concentration of anesthetic at which $50 \%$ of animals fail to respond to a painful stimulus (tail clamp) delivered at supramaximal intensity; animals were considered unresponsive only if there is no obvious major muscular movement in direct response to the tail clamp (Eger et al., 1965). Halothane and isoflurane (in oxygen) were delivered via a vaporizer to mice placed in a nose cone, with concentrations continuously monitored at the nose cone (CapnoMac, GE Healthcare). Rectal temperature was monitored and maintained at $36-38^{\circ} \mathrm{C}$ using a heating pad. After the 30-40 min equilibration periods at each anesthetic concentration, the tail was clamped for up to $45 \mathrm{~s}$ using hemostats; anesthetic concentration was increased stepwise $(\Delta+0.1 \%)$ until the animal failed to respond to the tail clamp. Although animals were exposed to anesthetics for $2-3 \mathrm{~h}$ in these assays, MAC values are known to be stable for $>8 \mathrm{~h}$ (Eger et al., 1965). For a measure of sedation, we incorporated an infrared mouse motion detector/data logger (Mouse-E-Motion, Infra-E-Motion) onto a flow-through veterinary anesthesia chamber (SurgiVet). The data logging system was set to detect movements of mice placed in this covered chamber on a second-to-second basis, and those values were summed over 5-10 min epochs for a control period (duration: $10 \mathrm{~min}$ ) and then during exposure to anesthetic:oxygen gas mixture; data thus represent the total number of seconds in an epoch when any movement took place. Anesthetic concentration in the chamber was continuously monitored (CapnoMac, GE Healthcare).
As a control for effects of TASK channel deletion on the anesthetic actions of inhalational agents, we also examined effects of etomidate, an intravenous anesthetic that has no effect on TASK channels. Bolus injections of etomidate $(10 \mathrm{mg} / \mathrm{kg})$ were administered via the tail vein, and latencies to regain the righting reflex and the paw withdrawal reflex were used as a measure of sensitivity to hypnotic and immobilizing actions, respectively (Garfield and Bukusoglu, 1996).

Data acquisition and analysis. Results are presented as mean \pm SEM. Data were analyzed statistically using one-way ANOVA or Student's $t$ test; post hoc pairwise comparisons used Bonferroni's correction of the $t$ test. We obtained $\mathrm{EC}_{50}$ values for anesthetic action by averaging the anesthetic concentration at which the reflex was lost in individual animals or from a logistic fit through grouped data (in Excel or Prism 3.0); the values obtained from these two methods were not different. In all cases, differences in mean values were considered significant if $p<0.05$.

\section{Results}

We previously described the derivation of global TASK channel knock-out mice on a mixed genetic background (Mulkey et al., 2007; Davies et al., 2008); for the present work, we primarily used homozygous TASK knock-out mouse lines that were maintained on a C57BL/6J background, with wild-type C57BL/6J mice serving as the control strain. We confirmed a number of cellular and behavioral effects of anesthetics in mice on both the C57BL/6J and mixed genetic background. In addition, we generated a new conditional knock-out line in which TASK channel deletion was restricted to cholinergic neurons. For all mouse lines, we verified loss of TASK expression, examined anesthetic-sensitive membrane properties in motoneurons, and determined the consequences of TASK channel deletion on clinically relevant anesthetic outcomes.

As with the lines described earlier (Mulkey et al., 2007), congenic TASK channel knock-out mice were viable and displayed no obvious sensorimotor deficits (data not shown). As expected based on earlier work from previously described TASK knockout lines (Aller et al., 2005; Brickley et al., 2007; Mulkey et al., 2007), we found no evidence for altered expression of other K2P channel genes in a microarray analysis of brainstem cDNA from either single or double congenic TASK channel knock-out mice (data not shown). Moreover, a directed quantitative reverse transcription PCR analysis revealed no difference in expression of the anesthetic-sensitive TREK-1 (K2P2.1) channel in brainstem of double TASK knock-out mice (supplemental Fig. S1, available at www.jneurosci.org as supplemental material).

\section{TASK channel deletion and diminished TASK-like currents in motoneurons from TASK knock-out mice}

TASK channel expression in motoneurons from congenic TASK knock-out lines was examined histochemically by nonisotopic in situ hybridization and functionally by whole-cell, patch-clamp electrophysiology. As shown in Figure 1, strong expression of both TASK-1 and TASK-3 subunits was observed in all pools of motoneurons examined in control C57BL/6J mice (i.e., facial, hypoglossal, spinal) (Talley et al., 2000; 2001; Karschin et al., 2001; Berg et al., 2004); as expected, hybridization signal for the relevant TASK channel subunit was diminished in single TASK knock-out mice, and there was no detectable expression of either subunit in motoneurons from double TASK $^{-1-}$ mice. Likewise, TASK expression was lost in other brain regions of knock-out mice where TASK-1, TASK-3, or both are typically expressed (e.g., locus ceruleus, dorsal raphe, striatum; data not shown) (Mulkey et al., 2007).

We performed whole-cell recordings from hypoglossal motoneurons in brainstem slices obtained from control and TASK 
channel knock-out mice. As shown in Figure $2 A$, we found that motoneurons from single and double TASK subunit knockout mice appeared to have normal firing properties; in response to depolarizing current pulses, cells from control and TASK knock-out mice were able to fire overshooting action potentials repetitively, with fast and medium afterhyperpolarizations that are typical of these neurons. However, as shown in Figure $2 B$ (left), motoneurons from TASK knockout mice were significantly depolarized in comparison to cells from control mice; resting membrane potential was $-77.8 \pm$ $1.0 \mathrm{mV}$ in control mice, but only approximately -70 to $-73 \mathrm{mV}$ in knock-out mice (TASK-1 ${ }^{-1-}$ : $-71.6 \pm 1.1 \mathrm{mV}$; TASK-3 ${ }^{-1-}:-73.4 \pm 1.0 \mathrm{mV}$; TASK $^{-1-}$ : $-72.3 \pm 1.6 \mathrm{mV} ; F_{(3,85)}=5.3, n \geq 15, p<$ $0.05)$. Accordingly, the standing outward current obtained at a holding potential of $-60 \mathrm{mV}$, shown in Figure $2 B$ (middle), was significantly greater in control mice than in any of the knock-out lines (control: $245.9 \pm 23.5$ pA; TASK-1 ${ }^{-1-}$ : $154.8 \pm 17.2$ pA; TASK-3 ${ }^{-1-}: 174.6 \pm$ $16.1 \mathrm{pA} ;$ TASK $^{-1-}: 142.6 \pm 19.1 \mathrm{pA}$; $\left.F_{(3,85)}=5.1, n \geq 15, p<0.05\right)$. We found no statistically significant differences in input conductance, although there was a trend toward lower conductance values in the knock-out lines $\left(F_{(3,85)}=2.1, n \geq 15\right.$, $p>0.11$ ).

In hypoglossal motoneurons from the rat, essentially all of the standing outward current sensitive to $\mathrm{pH}$ variations (from $\mathrm{pH} 8.4$ to $\mathrm{pH} 5.9$ ) appears to be due to TASK channels insofar as the instantaneous $I-V$ relationships of $\mathrm{pH}$-sensitive currents are well fitted by the GHK equation, with a reversal potential at the potassium equilibrium potential $\left(E_{\mathrm{K}}\right)$ (Talley et al., 2000). This was not the case in mouse hypoglossal motoneurons, where multiple channels appear to contribute to the overall $\mathrm{pH}$-sensitive current; this is most easily discerned by the lack of a clear reversal in instantaneous $I-V$ s of $\mathrm{pH}$-sensitive current from mouse motoneurons (Fig. 2C, left). Nevertheless, a contribution of TASK channels was clearly evident by comparing the magnitude of the $\mathrm{pH}$-sensitive current from wild-type and TASK knock-out mice (at $-60 \mathrm{mV}$ ), along with the corresponding $I-V$ curves. The $\mathrm{pH}$-sensitive current was diminished in each of the knock-out lines (control: $271.5 \pm 27.5 \mathrm{pA}$; TASK-1 ${ }^{-1-}: 99.2 \pm 9.4 \mathrm{pA}^{\text {TASK-3 }}{ }^{-1-}$ : $145.0 \pm 14.4 \mathrm{pA} ;$ TASK $^{-1-}: 57.4 \pm 5.8 \mathrm{pA} ; F_{(3,84)}=27.5, n \geq 14$, $p<0.0001$ ), and the weak outward rectification evident in the wild-type mice was reduced in single TASK subunit knock-outs and eliminated in double TASK $^{-1-}$ knock-out mice. The TASK-

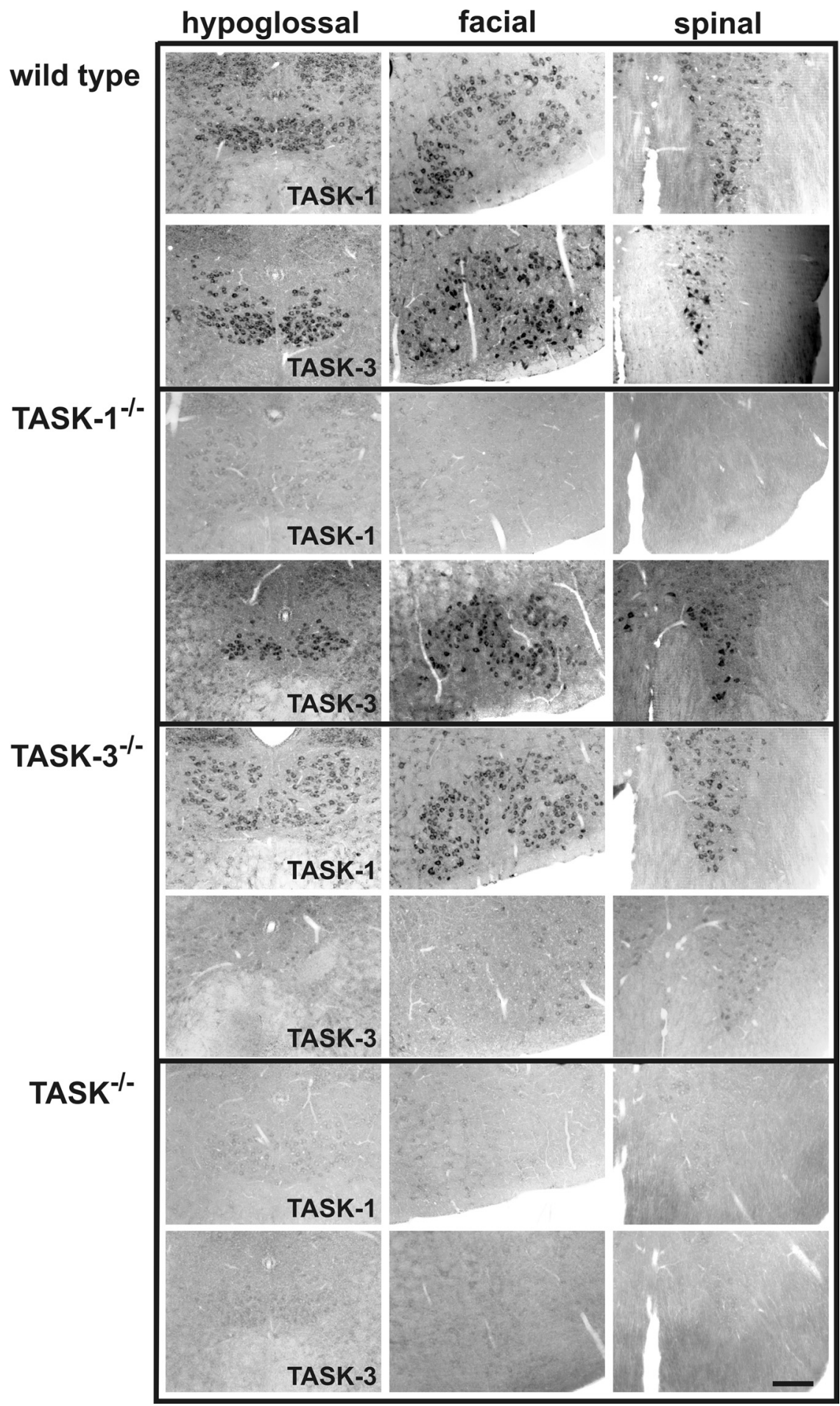

Figure 1. TASK channel subunits are deleted from motoneurons in TASK knockout mice. In situ hybridization was performed using digoxigenin-labeled cRNA probes on coronal sections $(30 \mu \mathrm{m})$ of brainstem and spinal cord from $C 57 \mathrm{BL} / 6 \mathrm{~J}$ mice that were wild type at the TASK alleles or deleted for TASK-1 (TASK- $1^{-1-}$ ), TASK-3 (TASK- $3^{-1-}$ ), or both TASK channel genes (TASK ${ }^{-1-}$ ). There was prominent expression of both TASK-1 and TASK-3 in hypoglossal, facial, and spinal motoneuron pools in sections from the wild-type mouse. In single TASK subunit knock-out mice, the hybridization signal representing the cognate transcript was diminished, and neither TASK-1 nor TASK-3 expression was detectable in the TASK ${ }^{-1-}$ double knock-out mice. Scale bar, $200 \mu \mathrm{m}$. dependent component of $\mathrm{pH}$-sensitive current, derived by subtracting $\mathrm{pH}$-sensitive currents obtained from wild-type and double TASK $^{-1-}$ knock-out mice, reversed near $E_{\mathrm{K}}$ and presented with the weakly rectifying $I-V$ expected for TASK currents (Fig. $2 C$, inset). Note that deletion of either TASK-1 or TASK-3 
A

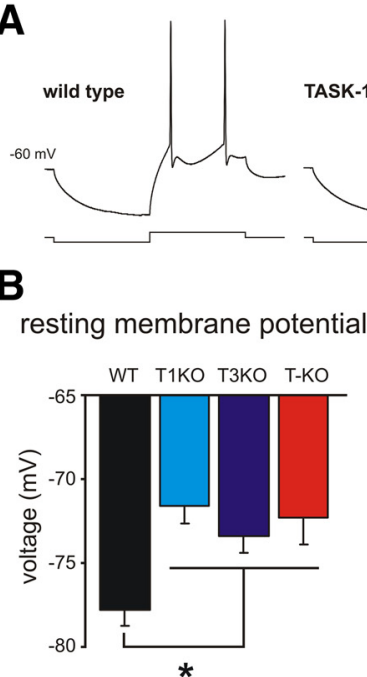

C

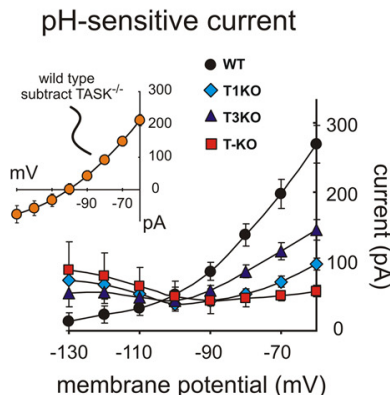

holding current
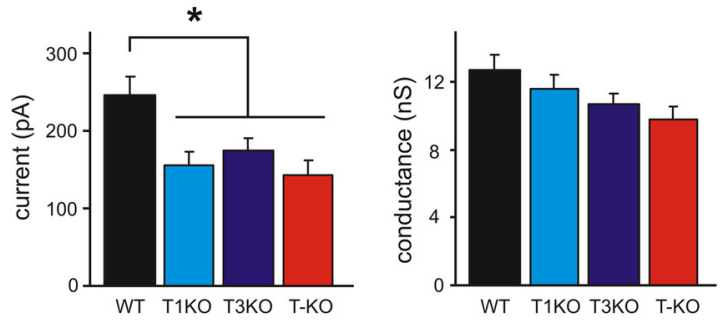

D

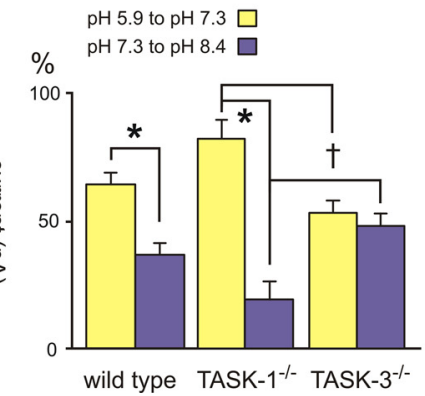

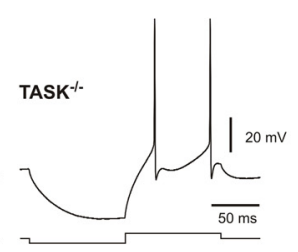

input conductance

formations are possible, the acidinhibited proportion of current was greater than the alkaline-activated component ( $\sim 64$ vs $\sim 36 \% ; n=12, p<0.05$ ), implying a $\mathrm{pKa}$ value lower than $\mathrm{pH}$ 7.3. In TASK- $1^{-1-}$ cells, where TASK-3 homomeric channels are the only possible TASK conformation, the apparent $\mathrm{pKa}$ shifted to lower $\mathrm{pH}$ values with substantially more acid-inhibited than alkalineactivated current $(~ \sim 85$ vs $\sim 15 \% ; n=17$, $p<0.05$ ); conversely, in motoneurons deleted for TASK-3, where TASK-1 homomeric channels are expected, we found approximately equal fractions of acid-inhibited and alkaline-activated current, implying a $\mathrm{pKa} \sim 7.3$ ( $\sim 49$ vs $\sim 51 \%$; $n=12)$. Comparing the two genotypes where only homomeric TASK channels are available (i.e., TASK- $1^{-1-}$ vs TASK$\left.3^{-1-}\right)$, the acid-inhibited $(84.6 \pm 6.5 \%$ vs $51.3 \pm 4.8 \%)$ and alkaline-activated $(15.4 \pm 6.4 \%$ vs $48.7 \pm 4.8 \%)$ currents were significantly different $(p<0.05)$. Although these data are most certainly confounded by the component of $\mathrm{pH}$ sensitive current that is not due to TASK channels, the apparent pKa values nevertheless approximated those expected for the resident populations of homomeric and/or heteromeric TASK channels, and the relative shifts in pKa were in the direction predicted for loss of the relevant TASK channel subunit.

In addition, since different conformations of TASK channels are known to be differentially sensitive to $\mathrm{Zn}^{2+}$ (TASK$3>$ TASK-1/TASK-3 $>$ TASK-1), we also examined inhibition by $\mathrm{Zn}^{2+}$ of the TASK-like current in motoneurons from wild-type and TASK knock-out mice (Fig. $2 D)$. As expected based on this sensitivity profile, $\mathrm{Zn}^{2+}$ inhibited the largest fraction of current in TASK-1 $1^{-1-}$ motoneurons (i.e., in cells predicted to express TASK-3 accounted for more than half of the overall TASK-dependent $\mathrm{pH}$-sensitive current ( $\sim 80$ and $\sim 60 \%$, respectively), such that the respective contributions sum to $>100 \%$ of the total current. This superadditive interaction suggests that a component of TASK current in motoneurons is carried by heterodimeric TASK channels, as expected from our previous results in rat motoneurons (Berg et al., 2004).

As mentioned, in earlier work we attributed substantial fractions of motoneuronal TASK-like currents to TASK-1 and TASK-3 homomeric and TASK-1/TASK-3 heterodimeric channels (Berg et al., 2004). Each of these different TASK channel conformations presents with unique $\mathrm{pKa}$ for channel inhibition (pKa values: TASK-1, 7.3-7.4; TASK-3, 6.5-6.7; TASK-1/ TASK-3, 7.0-7.2). Accordingly, we found the expected shifts in proportions of current inhibited by acidification (from $\mathrm{pH} 7.3$ to $\mathrm{pH}$ 5.9) and activated by alkalization (from $\mathrm{pH} 7.3$ to $\mathrm{pH} 8.4$ ) in motoneurons from TASK-1 and TASK-3 knock-out mice (Fig. $2 C$, right). In cells from wild-type mice, where all channel con-

homomeric channels; $59.2 \pm 5.3 \%, n=13$ ), an intermediate fraction in wild-type motoneurons (i.e., where all channel conformations are possible; $37.4 \pm 6.6 \%$ of the current, $n=9)$ and the smallest fraction in TASK- $3^{-1-}$ motoneurons (i.e., in cells predicted to express TASK-1 homomeric channels; $14.9 \pm 3.5 \%$, $n=7)$.

Together, these histochemical and electrophysiological data verify deletion of the cognate TASK channel subunit in the different TASK knock-out mouse lines. In addition, they indicate that both TASK-1 and TASK-3 contribute to previously described motoneuronal TASK-like currents (Talley et al., 2000; Berg et al., 2004), likely in both homomeric and heteromeric conformations.

Motoneuronal anesthetic-activated $\mathrm{K}^{+}$currents are reduced in mice deleted for TASK-1 or TASK-3 and absent in double TASK knock-out mice

We have suggested that TASK channels account for an anestheticactivated background $\mathrm{K}^{+}$current in rat motoneurons, based on 

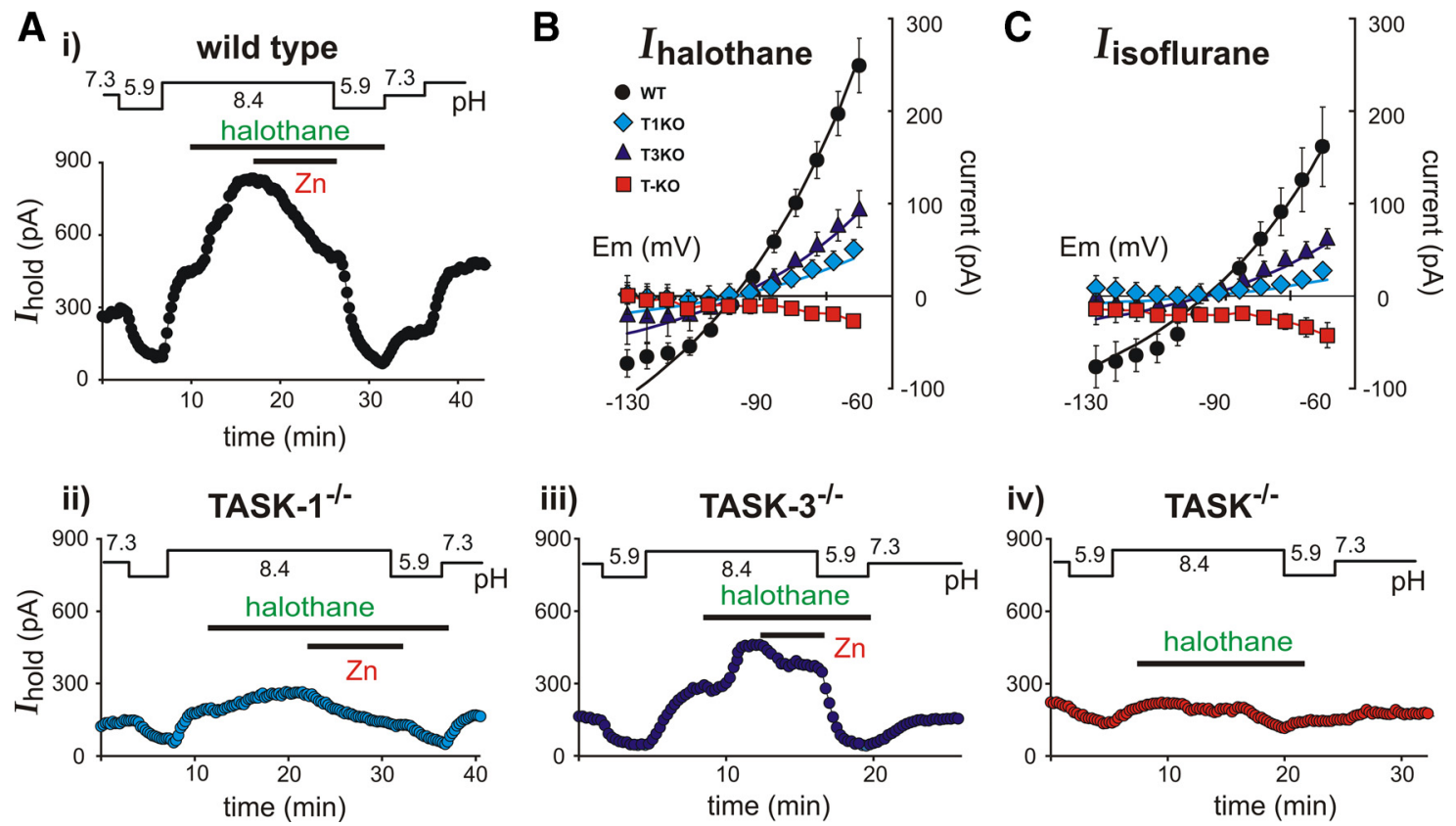

Figure 3. Anesthetic-sensitive currents in motoneurons from TASK knock-out mice. $A$, Representative time series of holding current $\left(I_{\text {hold }}\right.$; at $\left.-60 \mathrm{mV}\right)$ in individual motoneurons from wild-type (i) and TASK knock-out (ii-iv) mice during exposure to acidified ( $\mathrm{pH} \mathrm{5.9)}$ and alkalized ( $\mathrm{pH}$ 8.4) bath solutions, the inhalational anesthetic halothane (0.8 mM), and a discriminating concentration of $\mathrm{Zn}^{2+}(100 \mu \mathrm{M}) . \boldsymbol{B}$, The halothane-activated current was derived in motoneurons from wild-type (WT) and TASK knock-out lines (T1KO, TASK- $1^{-1-} ;$ T3KO, $^{\text {TASK- }} 3^{-1-} ;$ T-KO, TASK $^{-1-}$ ) by digital subtraction of control currents from those measured in the presence of halothane; those values were averaged ( \pm SEM) and plotted over a range of membrane potentials. The data from wild-type and single subunit TASK knock-out mice were fitted with the GHK equation. C, Likewise, the current activated by isoflurane was derived in motoneurons by digital subtraction of control currents from those measured in the presence of $0.5 \mathrm{~mm}$ isoflurane, averaged ( \pm SEM), plotted versus membrane potential, and fitted with GHK equations.

the observation that this current displays instantaneous GHK rectification and inhibition by extracellular acidification, hallmark properties of TASK channels (Sirois et al., 2000; Berg et al., 2004). Thus, we tested here whether wild-type mouse motoneurons also express a TASK-like, anesthetic-activated background $\mathrm{K}^{+}$current, and we used our knock-out mice to determine whether such a current can be attributed to TASK channels.

As depicted in Figure $3 \mathrm{~A}$ for a representative wild-type motoneuron, bath acidification (from $\mathrm{pH} 7.3$ to $\mathrm{pH}$ 5.9) decreased outward holding current at $-60 \mathrm{mV}$ and bath alkalization (to $\mathrm{pH}$ 8.4) increased outward current; in the alkalized bath, administration of the inhalational anesthetic halothane $(0.8 \mathrm{~mm})$ further increased the outward current. The $\mathrm{pH}$ - and halothane-sensitive current in this cell was partially inhibited by $100 \mu \mathrm{M} \mathrm{Zn}{ }^{2+}$ and totally eliminated by a second bout of bath acidification. The voltage-dependent properties of the halothane-sensitive current were characterized by digital subtraction of instantaneous $I-V$ curves in the presence and absence of halothane (i.e., the $I-V$ at $\mathrm{pH} 8.4$ was subtracted from the $I-V$ in halothane at $\mathrm{pH} 8.4$ ); as shown in Figure $3 B$, the averaged $I-V$ relationship for this halothane-activated current was well fitted by the GHK equation in wild-type mouse motoneurons $(n=13)$. These results are similar to those we reported earlier in rat motoneurons (Sirois et al., 2000; Berg et al., 2004).

As described above, the $\mathrm{pH}$-sensitive current was strongly diminished in motoneurons from either TASK- $1^{-1}$ or TASK$3^{-1-}$ mice (Fig. 2); the lower three records of Figure $3 A$ show that the halothane-activated current was also reduced in these cells. The residual halothane-activated outward current was mediated by the remaining homomeric TASK channels in motoneurons from single TASK subunit knock-out mice, since the averaged $I-V$ values of halothane-sensitive current were well fitted by a
GHK equation (Fig. 3B) and halothane failed to evoke an outward current in double TASK ${ }^{-1-}$ knock-out mice. In fact, halothane induced a consistent, albeit small, inward shift in holding current in motoneurons from double $\mathrm{TASK}^{-1-}$ knock-out mice. The averaged halothane-activated current in motoneurons from each of the knock-out lines was significantly reduced (Fig. $3 B$ ) in comparison to that from wild-type mice (halothane-activated current at $-60 \mathrm{mV}$ : control, $249.1 \pm 29.5 \mathrm{pA}$; TASK- $1^{-1-}$,

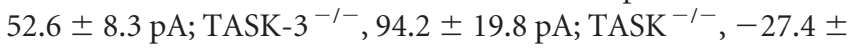
$5.4 \mathrm{pA} ; n \geq 8, p<0.05)$.

We obtained essentially identical results with $0.5 \mathrm{~mm}$ isoflurane, a different class of inhalational anesthetic (Fig. 3C). The averaged current amplitude was slightly smaller for isoflurane than for halothane in wild-type motoneurons, but the differences between wild-type and knock-out lines were highly significant (isoflurane-activated current at $-60 \mathrm{mV}$ : control, $161.7 \pm 43.1$ pA; TASK- $1^{-1-}, 28.2 \pm 4.7$ pA; TASK- $3^{-1-}, 62.3 \pm 10.7$ pA; TASK $\left.^{-1-},-42.3 \pm 13.4 \mathrm{pA} ; n \geq 6, p<0.05\right)$. It is important to mention that we previously reported that isoflurane differentially modulates rat TASK (rTASK) channel clones expressed heterologously, with rTASK-1 less sensitive to isoflurane than rTASK-3 (Berg et al., 2004). However, we found here that isoflurane is able to activate the mouse TASK-1 channel (supplemental Fig. S2, available at www.jneurosci.org as supplemental material), accounting for the ability of isoflurane to enhance current in TASK- $3^{-1-}$ mice, where only homomeric TASK-1 channels should persist.

Thus, these data indicate that the $\mathrm{K}^{+}$current activated by inhalational anesthetics in mouse motoneurons is indeed due to TASK channels; they also predict that anesthetic-induced changes in excitability that are mediated by TASK channels will be absent in TASK knock-out mice. 

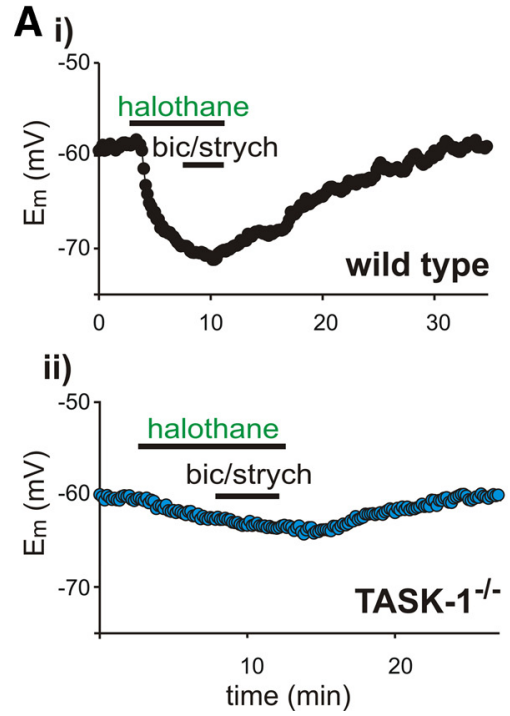

B

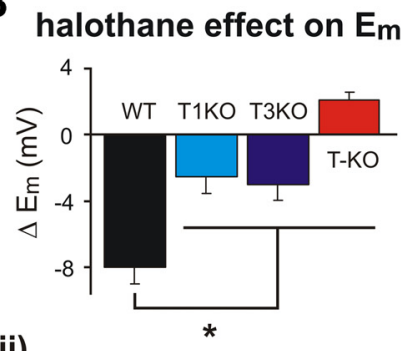

iii)

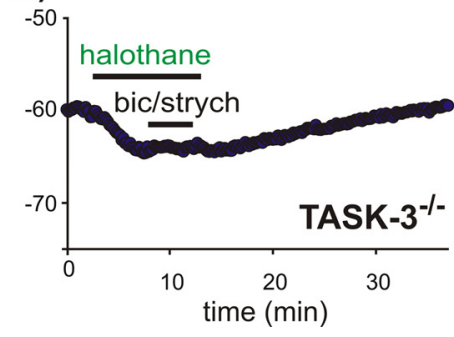

C isoflurane effect on $E_{m}$

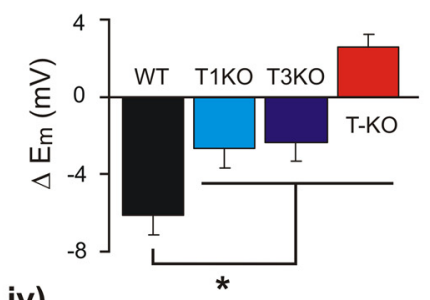

iv)

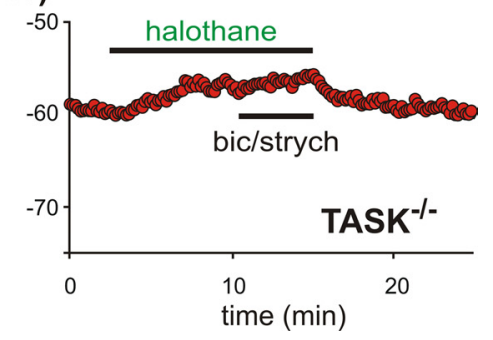

Figure 4. Effects of anesthetics on membrane potential $\left(E_{\mathrm{m}}\right)$ in motoneurons from TASK knock-out mice. $\boldsymbol{A}$, Representative time series of membrane potential changes in response to application of halothane $(0.8 \mathrm{~mm}$ ) and a bicuculline/strychnine (bis/strych) mixture (at 10 and $30 \mu \mathrm{m}$ ) in individual motoneurons from wild-type (i) and TASK knock-out mice (ii- $\boldsymbol{v}$ ); we used DC current injection to set all cells to the same initial membrane potential $(-60 \mathrm{mV})$. $\boldsymbol{B}$, The averaged change in membrane potential ( \pm SEM) induced by halothane in motoneurons from wild-type (WT) and TASK knock-out lines (T1KO, TASK-1 ${ }^{-1-} ;$ T3KO, TASK-3 $3^{-1-} ;$ T-KO, TASK $^{-1-}$ ). C, The averaged change in membrane potential ( \pm SEM) induced by 0.5 mm isoflurane in motoneurons from wild-type and TASK knock-out lines. ${ }^{*} p<0.05$ vs wild type.

\section{Reduced anesthetic-evoked membrane hyperpolarization in TASK knock-out mice}

We performed current-clamp analysis of motoneuronal responses to anesthetics in the absence of blockers of other anesthetic-sensitive channels (e.g., $\mathrm{GABA}_{\mathrm{A}}, \mathrm{HCN}$ ) to assess overall effects of the drugs on membrane potential. As shown in Figure $4 A$, halothane $(0.8 \mathrm{~mm})$ caused a strong membrane hyperpolarization in a representative motoneuron from a wild-type mouse (approximately $-12 \mathrm{mV}$ ); halothane evoked smaller hyperpolarizations in motoneurons from TASK-1 ${ }^{-1-}$ and TASK$3^{-I-}$ mice (approximately -4 to $-5 \mathrm{mV}$ ) and actually caused a slight depolarization in the cell from a double TASK ${ }^{-1-}$ knockout mice $(\sim 3 \mathrm{mV})$. Averaged data reveal significantly different effects on membrane potential between wild-type and TASK knock-out lines for halothane (Fig. $4 B$ ) (control, $-8.0 \pm 1.1 \mathrm{mV}$; TASK $-1^{-1-},-2.5 \pm 0.3 \mathrm{mV}$; TASK- $3^{-1-},-3.0 \pm 0.6 \mathrm{mV}$; TASK $\left.^{-1-},+2.1 \pm 0.5 \mathrm{mV} ; n \geq 6, p<0.05\right)$ and for $0.5 \mathrm{~mm}$ isoflurane (Fig. 4C) (control, $-6.1 \pm 0.7 \mathrm{mV}$; TASK-1 ${ }^{-1-}$, $-2.7 \pm 0.4 \mathrm{mV}$; TASK $-3^{-1-},-2.3 \pm 0.3 \mathrm{mV}$; TASK $^{-1-},+2.6 \pm$ $0.6 \mathrm{mV} ; n \geq 6, p<0.05)$. These current-clamp results are entirely consistent with voltage-clamp data where anesthetics activated smaller outward currents in single TASK subunit knock-out mice and an inward current shift in double TASK $^{-1-}$ knock-out mice. Note also that a bicuculline/strychnine mixture applied during anesthetic administration had essentially no effect on membrane potential in motoneurons, regardless of TASK genotype (Fig. 4A).

\footnotetext{
Anesthetic-induced immobilization and halothane-evoked sedation and hypnosis are reduced in TASK knock-out mice We examined effects of TASK channel deletion on three key features of anesthetic action-immobilization, hypnosis, and sedation- using behavioral assays in mice. For immobilization and hypnosis, respectively, we determined the anesthetic concentration at which half the animals failed to respond to a tail or paw pinch (MAC) or failed to right themselves when placed on their backs (MAC-awake, LORR); for sedation, we adapted an infrared
}

motion detector system to record effects of anesthetic exposure on overall activity.

For all TASK channel knock-out lines, whether single subunit deletion or double TASK $^{-1-}$ knock-outs, a significantly higher concentration of halothane or isoflurane was required to render mice unresponsive to a tail pinch in comparison with wildtype mice (Fig. 5A); anesthetic sensitivity was not different when compared across the TASK knock-out lines. The insets in Figure $5 \mathrm{~A}$ plot averaged values of MAC obtained for each of the genotypes (halothane: C57BL/6J, $0.97 \pm 0.01$; TASK$1^{-l-}, 1.10 \pm 0.03$; TASK-3 $3^{-1-}, 1.16 \pm 0.02$ TASK $^{-1-}, 1.13 \pm$ $0.03 ; n \geq 10, F_{(3,48)}=14.8, p<0.001$; isoflurane: $\mathrm{C} 57 \mathrm{BL} / 6 \mathrm{~J}$, $1.30 \pm 0.01 ;$ TASK $-1^{-1-}, 1.39 \pm 0.02$; TASK- $3^{-l-}, 1.40 \pm$ 0.02 TASK $\left.^{-1-}, 1.43 \pm 0.02 ; n \geq 10, F_{(3,60)}=6.7, p<0.001\right)$. Thus, sensitivity to immobilizing actions of both anesthetics was reduced by TASK channel deletion.

Compared with wild-type mice, a higher concentration of halothane was required to interfere with the righting reflex for all lines of TASK knock-out mice (Fig. 5B); among the different TASK knock-out lines, however, there was no difference in $\mathrm{EC}_{50}$ values (halothane: C57BL/6J, $0.70 \pm 0.01$; TASK-1 ${ }^{-1-}, 0.84 \pm$ 0.01 ; TASK $-3^{-1-}, 0.83 \pm 0.01$ TASK $^{-\prime-}, 0.81 \pm 0.02 ; n \geq 6, p<$ $0.05)$. By contrast, the LORR induced by isoflurane occurred at the same concentration in all mouse lines (isoflurane: $\mathrm{C} 57 \mathrm{BL} / 6 \mathrm{~J}$,

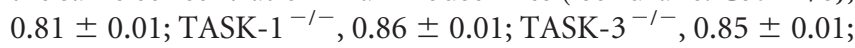
$\left.\mathrm{TASK}^{-1-}, 0.82 \pm 0.02 ; n \geq 18\right)$. These data indicate that there is no effect of TASK channel deletion on isoflurane-induced hypnosis, but a slight decrease in hypnotic sensitivity to halothane in TASK knock-out mice.

We also found that TASK knock-out mice were less sensitive to sedating actions of halothane. As shown in Figure $5 C$, we tracked movements as a function of time for mice exposed to $0.6 \%$ halothane and $0.7 \%$ halothane; whereas wild-type mice were sedated by $\sim 15-20$ min into the $0.6 \%$ halothane exposure, TASK knock-out mice remained active throughout much of the $40 \mathrm{~min}$ of exposure to $0.6 \%$ halothane and only reached the same low level of activity after $\sim 10 \mathrm{~min}$. of exposure to $0.7 \%$ halothane 
(Fig. 5C, left). The striking difference in sedative actions of halothane is even more apparent in the time integral of these data (i.e., the total movement time) (Fig. 5C, right); by this measure, all TASK knockout lines were equally resistant to the sedative actions of halothane. The difference in activity was caused by the anesthetic and was not a reflection of some other effect of TASK channel deletion on overall activity levels; wild-type and TASK knock-out mice had essentially identical activity levels during the initial control period, and although activity decreased somewhat over the same time period in control experiments without exposure to halothane, the levels were not different across genotypes (Fig. 5C, left, filled symbols). Interestingly, mirroring the agent-specific actions of halothane and isoflurane on hypnosis, we found no significant difference in effects of isoflurane on TASK knock-out mice in this same assay (data not shown). Thus, hypnotic and sedative actions of halothane, but not isoflurane, appear to be blunted in TASK knock-out mice; on the other hand, the sensitivity to immobilizing actions of both drugs is reduced in TASK knock-out lines. For all assays, there were no differences in relative anesthetic sensitivity between single subunit TASK knock-outs and double TASK $^{-1-}$ mice.

We performed control experiments to rule out the possibility that observed differences in anesthetic sensitivity of TASK knock-out mice reflect some general change in excitability associated with deletion of the widely expressed TASK channels. As shown in Figure 6, we found that the intravenous anesthetic etomidate had no effect on heterologously expressed homomeric TASK-1 and TASK-3 channels or a concatenated TASK-1/TASK-3 heterodimeric channel. Importantly, neither the immobilizing nor the hypnotic actions of etomidate $(10 \mathrm{mg} / \mathrm{kg}$, i.v.) were affected in TASK knock-out mice; the duration of the loss-of-hindlimb withdrawal reflex and the LORR measured in TASK- $1^{-1-}$, TASK $-3^{-1-}$, and TASK $^{-1-}$ mice were not different from those obtained in wildtype C57BL/6J mice. Together, these data suggest that the diminished sensitivity of TASK knock-out mice to inhaled anesthetics is unlikely to be due to general changes in excitability that nonspecifically affect responses to all anesthetics.

\section{Effects of TASK channel deletion on cellular and behavioral responses to inhaled anesthetics were similar in TASK knock-out mice on a mixed genetic background}

We performed similar studies in control and TASK channeldeleted littermates derived from crosses of heterozygous animals on a mixed genetic background (C57BL/6J and 129 substrains) (Mulkey et al., 2007; Davies et al., 2008). As described below, data mice during exposure to halothane.

\section{isoflurane MAC}

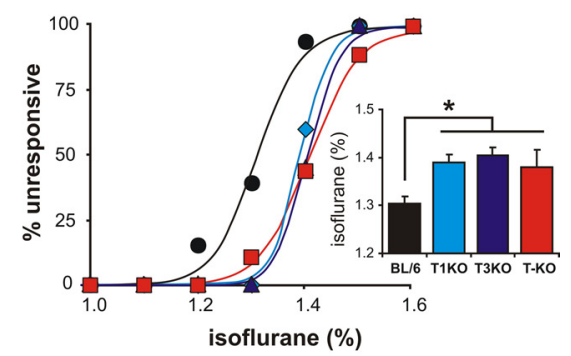

isoflurane LORR
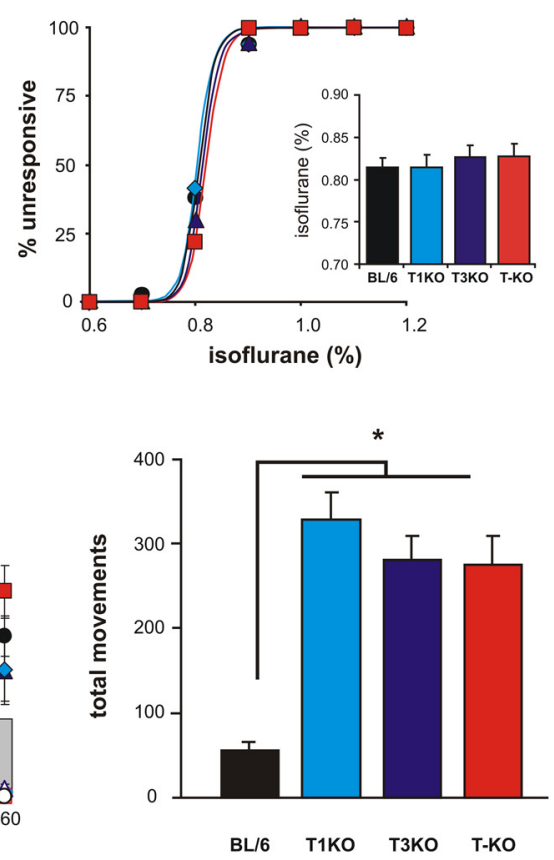

Figure 5. Behavioral actions of inhaled anesthetics in TASK knock-out mice. $A, B$, At incrementing concentrations of halothane 0.5-1.4\%, percentage inspired concentration) or isoflurane (0.6-1.6\%), the percentage of wild-type (WT) and TASK knock-out ; $33 K_{0}$, TASK-3 $^{-}$; T-KO, TASK $^{-1-}$ ) that failed to make a purposeful movement in response to a tail 列 points represent best fits to logistic equations. $C$, Sedative effects of halothane in wild-type and TASK knock-out mice were

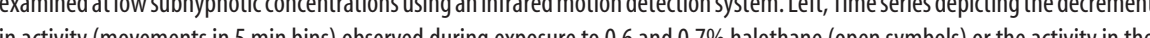
same groups of animals not exposed to anesthetic (filled symbols; only shown at initial and final time points for clarity). Right, Integrated activity levels (averaged total movements throughout the entire recording period) for wild-type and TASK knock-out

from these studies indicate that observed differences in congenic TASK knock-out mice were also apparent in the context of this mixed genetic background.

In these mice, we again found that halothane-induced outward currents were reduced in hypoglossal motoneurons from single and double TASK channel knock-out mice; however, the anesthetic-activated currents were eliminated even with single TASK subunit knock-outs on this mixed genetic background, suggesting that heterodimeric TASK channels were predominant in this setting (supplemental Fig. S3A,B, available at www. jneurosci.org as supplemental material). Under current clamp, the effects of isoflurane were essentially identical to those observed on the C57BL/6J background: a robust, 6-8 $\mathrm{mV}$ hyperpolarization evoked by isoflurane in control mice, but only a small 
A

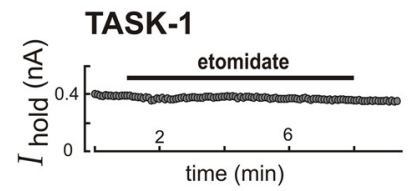

TASK-3

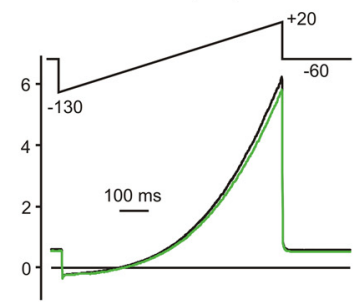

C

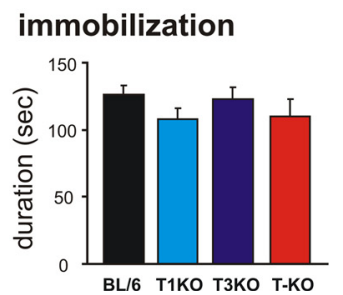

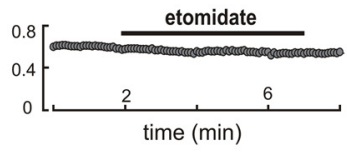
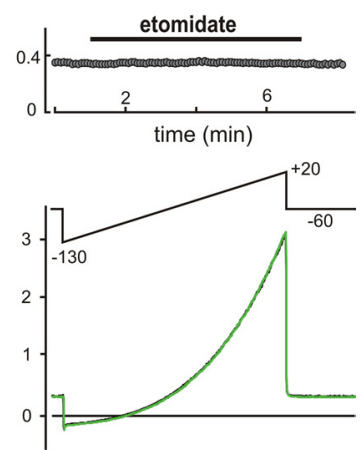

hypnosis

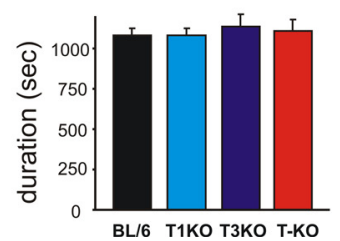

Figure 6. Etomidate does not modulate TASK channels, and its behavioral effects are fully retained in TASK knock-out mice. A, HEK293 cells were transfected with TASK-1, TASK-3, or a concatenated TASK-1-TASK-3 construct and ramp voltage commands $(-130 \mathrm{mV}$ to $20 \mathrm{mV}, 0.1 \mathrm{~V} / \mathrm{s}$ at $0.2 \mathrm{~Hz}$ ) were used to elicit TASK currents before and during exposure to $10 \mu \mathrm{m}$ etomidate. Top, Holding current at $-60 \mathrm{mV}$. Bottom, Sample currents obtained under control conditions and in the presence of etomidate. $B$, Averaged current density at $-60 \mathrm{mV}$ ( \pm SEM, $n \geq 5$ ) for the different TASK channel constructs in control and etomidate; there was no effect of etomidate on homomeric or heteromeric TASK channels $\left(F_{(1,30)}=0.2, p>0.6\right.$, by two-way ANOVA).C, Wild-type and TASK knock-out mice were injected with etomidate ( $10 \mathrm{mg} / \mathrm{kg}$, i.v., $n \geq 7)$; sensitivities to immobilizing and hypnotic actions of etomidate were determined by the duration of the loss-of-paw-withdrawal and the loss-of-righting reflex, respectively. There was no difference among genotypes in either of these measures of etomidate sensitivity. By ANOVA, for LOPW: $F_{(3,43)}=1.2, p>$

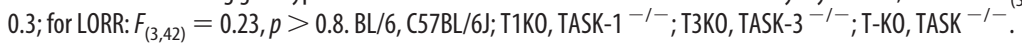

TASK-1/TASK-3

(supplemental Fig. S4, available at www. jneurosci.org as supplemental material). The close correspondence of data from these different lines of TASK knock-out mice is reassuring and provides strong support that observed changes in anesthetic sensitivity are not dependent on a specific genetic background.

Selective ablation of TASK channels in cholinergic neurons also eliminates motoneuronal anesthetic-activated TASK currents

The data presented to this point suggest that TASK channels are indeed molecular substrates for actions of inhaled anesthetics; they contribute to establishing the sensitivity for hypnotic/sedative effects of halothane and for immobilizing effects of both halothane and isoflurane. However, these experiments from global knock-out mice do not address potential neuronal substrates for these TASK channel contributions. In this regard, we chose to focus our further experiments on the role of TASK channels in motoneurons because of the robust effect of TASK gene deletion on immobilization and the strong rationale for predicting that immobilizing effects mediated by TASK channels are due to their prominent expression in motoneurons (Kendig, 1993; Zhou et al., 1997; 1998; Sirois et al., 2000; Karschin et al., 2001; Talley et al., 2001; Rudolph and Antkowiak, 2004).

residual isoflurane-induced hyperpolarization in single TASK subunit knock-out mice and a slight depolarization in the double TASK $^{-1-}$ mice (supplemental Fig. S3C,D, available at www. jneurosci.org as supplemental material). Again, there was essentially no effect of bicuculline or strychnine on anesthetic-induced membrane potential changes in any of the mouse lines (supplemental Fig. S3C, available at www.jneurosci.org as supplemental material). Thus, the data from this set of experiments are generally equivalent to those obtained with the congenic C57BL/6J mice, and they are consistent with the idea that TASK channel deletion strongly reduces inhibitory effects of inhaled anesthetics on motoneurons.

As with the cellular data from mice on this mixed genetic background, we also found behavioral effects of halothane and isoflurane that were similar to those from mice on the C57BL/6J background. For both anesthetic compounds, the sensitivity to immobilizing actions was significantly reduced (see supplemental Fig. S4, available at www.jneurosci.org as supplemental material); note that MAC values obtained from control animals with the mixed background were essentially identical to those from wild-type mice on the C57BL/6J background, and the shift in MAC for halothane and isoflurane was also similar for these TASK knock-out lines in comparison with their congenic counterparts (compare Fig. 5). Likewise, hypnotic actions of both halothane and isoflurane were affected by TASK deletion in these mixed lines similarly as in the congenic animals; TASK knock-out lines showed a slight reduction in sensitivity to halothane in the LORR assay but no difference in isoflurane sensitivity
To achieve more restricted TASK channel deletion, we crossed our mice bearing floxed TASK alleles with various mouse lines engineered for Cre expression directed to motoneurons. We did not observe appropriate TASK channel deletion when using a number of relatively motoneuron-selective Cre-expressing mouse lines, including GM53-Cre, Isl1-Cre, Olig1-Cre, and Olig2-Cre lines (Srinivas et al., 2001; Lu et al., 2002; Gong et al. 2007); with GM53-Cre, Isl1-Cre, and Olig2-Cre lines we found inadequate excision at the TASK loci as determined by in situ hybridization and/or electrophysiological recording (data not shown), and with Olig1-Cre mice we noted frequent germline transmission (i.e., we discovered gene deletion in offspring that were negative for Cre). However, we were able to obtain knockout of TASK channels in motoneurons by crossing TASK- ${ }^{\mathrm{f} / \mathrm{f}}$ : TASK $-3^{\mathrm{f} / \mathrm{f}}$ mice (hereafter called TASK ${ }^{\mathrm{f} / \mathrm{f}}$ mice) with a ChAT-Cre knock-in mouse line in which Cre expression is directed selectively to cholinergic neurons, including motoneurons.

As shown in Figure $7 A$, we found that TASK expression appeared normal in control TASK ${ }^{\mathrm{f} / \mathrm{f}}$ mice without Cre, whereas TASK channel transcripts were undetectable in motoneurons from floxed littermate animals that express Cre. It is important to point out that TASK expression was also eliminated in other groups of cholinergic neurons; this is exemplified by the loss of immunostaining for TASK-3 in ChAT-immunoreactive neurons of the basal forebrain and striatum (supplemental Fig. S5, available at www.jneurosci.org as supplemental material), cell groups that typically express high levels of TASK-3 in control animals (Karschin et al., 2001; Talley et al., 2001; Berg et al., 2004; Berg 
and Bayliss, 2007). By contrast, TASK expression was preserved in other, neurochemically distinct cell populations (e.g., serotonergic raphe nuclei, noradrenergic locus ceruleus) (supplemental Figs. S5, S6, available at www.jneurosci.org as supplemental material).

We examined membrane properties of motoneurons from ChAT-Cre-expressing TASK $^{\mathrm{f} / \mathrm{f}}$ mice and verified the loss of TASK channel currents in those cells (Fig. $7 B$ ). As with motoneurons from global TASK knock-out mice, we found that Cre-expressing TASK $^{\mathrm{f} / \mathrm{f}}$ mice were significantly depolarized in comparison with control TASK ${ }^{\mathrm{f} / \mathrm{f}}$ mice (control: $-73.9 \pm$ $2.4 \mathrm{mV} ;$ Cre $^{+}:-67.3 \pm 0.7 \mathrm{mV} ; n=9$ and 26 , respectively, $p<0.005)$, and the outward holding current at $-60 \mathrm{mV}$ was correspondingly reduced (control: $265.3 \pm 56.2 \mathrm{pA}$; Cre+: $88.7 \pm 7.6 \mathrm{pA}$; $n=9$ and 26, respectively, $p<0.0001)$. As expected, the decreased outward current was accompanied by diminished TASKlike $\mathrm{pH}$-sensitive currents in motoneurons from Cre-expressing mice (Fig. $7 B$ ) in comparison with those from control TASK $^{\mathrm{f} / \mathrm{f}}$ mice (control: $186.1 \pm 40.2 \mathrm{pA}$; Cre+: $37.1 \pm 6.7 \mathrm{pA} ; n=9$ and 26 , respectively, $p<0.0001)$. In addition, as shown in the exemplar voltage-clamp records of Figure $7 C$ (upper left), a robust halothane-activated, acid-inhibited outward $\mathrm{K}^{+}$current was observed in the motoneuron from a Cre-negative control mouse, whereas halothane caused only a slight inward shift in membrane current in the Cre-positive motoneuron (Fig. 7C, lower left). Indeed, there was a marked reduction in currents activated by either halothane (control: $165.5 \pm 17.1 \mathrm{pA}$; $\mathrm{Cre}^{+}:-36.4 \pm 6.0 \mathrm{pA} ; n=6$ and 19 , respectively, $p<0.0001$ ) or isoflurane (control: $116.2 \pm 38.7 \mathrm{pA} ; \mathrm{Cre}^{+}:-10.0 \pm 8.2$ $\mathrm{pA} ; n=3$ and 7 , respectively, $p<0.005$; see supplemental Fig. S7, available at www.jneurosci.org as supplemental material) in $\mathrm{Cre}^{+}$motoneurons. Under current clamp (Fig. 7C, right), halothane caused membrane hyperpolarization in motoneurons from control mice but had no effect on membrane potential in Cre-expressing TASK- ${ }^{\mathrm{f} / \mathrm{f}}$ :TASK- $3{ }^{\mathrm{f} / \mathrm{f}}$ mice; these differences were reflected in averaged data for halothane (control: $-6.6 \pm 0.5 \mathrm{mV} ;$ Cre $^{+}: 0.4 \pm 0.6 \mathrm{pA} ; n=3$ and 4, respectively, $p<$ $0.001)$ and were seen also with isoflurane (control: $-5.9 \pm 0.2$ $\mathrm{mV}$; Cre ${ }^{+}: 0.2 \pm 0.8 \mathrm{pA} ; n=6$ and 4 , respectively, $p<0.001$; see supplemental Fig. S7, available at www.jneurosci.org as supplemental material). Again, as in the experiments with global knockout lines, we found no effect of a bicuculline/strychnine mixture on membrane potential in the presence of either anesthetic in motoneurons from control or $\mathrm{Cre}^{+}$mice $(\leq 1 \mathrm{mV})$.

Overall, these data from control and ChAT-Cre mice were essentially identical to those obtained from wild-type and global TASK $^{-1-}$ double knock-out mice (compare Figs. 2-4). More-
B

\section{pH-sensitive current}

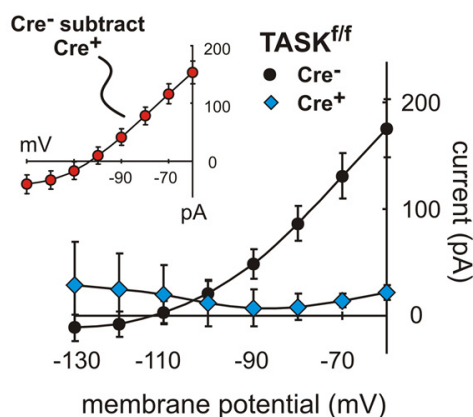

current clamp
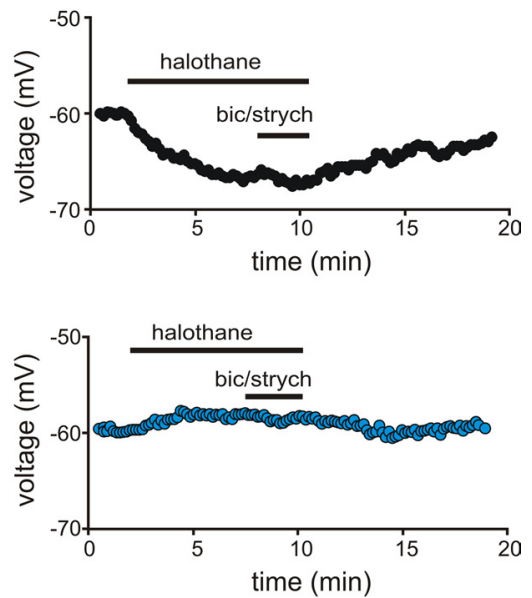

Figure 7. Effect of selective TASK channel deletion on motoneuronal properties and anesthetic actions. $\boldsymbol{A}$, Nonisotopic in situ ( motoneurons from $\mathrm{Cre}^{-}$- nd $\mathrm{Cre}^{+}$mice by digital subtraction of currents masured tained in an alkalized bath ( $\mathrm{pH} 8.4$ ); those values were averaged ( \pm SEM) and plotted over a range of membrane potentials. mponent of pH-sensitive current influenced by (re expression was determined by subtracting the $\mathrm{pH}$-sensitive current f $\mathrm{Cre}^{+}$motoneurons from that of control $\mathrm{Cre}^{-}$motoneurons. C, Left, Representative time series of holding current (at $-60 \mathrm{mV}$ ) (bottom) mice during exposure to acidified (pH 5.9), alkalized perfusate ( $\mathrm{pH}$ 8.4), and $0.8 \mathrm{~mm}$ halothane. Right, Effects of halothane and bicuculline/strychnine (bic/strych) mixture on membrane potential in representative motoneurons from $\mathrm{Cre}^{-}$(top) and $\mathrm{Cre}^{+}$(bottom) mice.

over, it is also worth pointing out that whereas anesthetics evoked outward currents that were $\geq 75 \mathrm{pA}$ in $100 \%$ of control motoneurons, a small anesthetic-induced outward current was only observed in 2/26 cells (of 3 and $30 \mathrm{pA}$ ); correspondingly, $100 \%$ of control cells hyperpolarized in the presence of the anesthetics (by at least $-3.5 \mathrm{mV}$ ), but we never saw this membrane hyperpolarization in ChAT-Cre-expressing neurons. This implies that TASK channels were deleted in the majority of motoneurons from the ChAT-Cre-expressing mice.

TASK channel deletion in cholinergic neurons diminishes sensitivity to immobilizing effects of anesthetics and sedating actions of halothane

To examine whether this more selective deletion of TASK channels also yielded a change in immobilizing effects of anesthetics, we performed MAC assays for halothane and isoflurane using 
A

\section{halothane MAC}

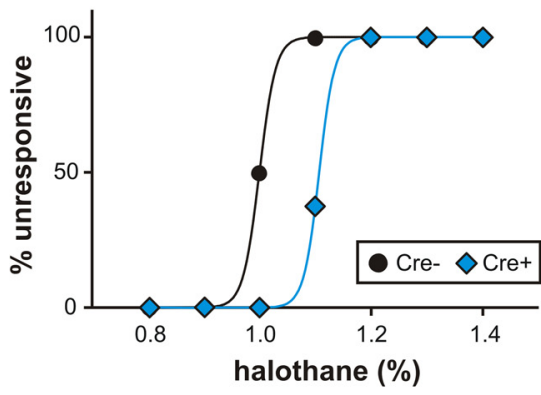

B

\section{halothane LORR}

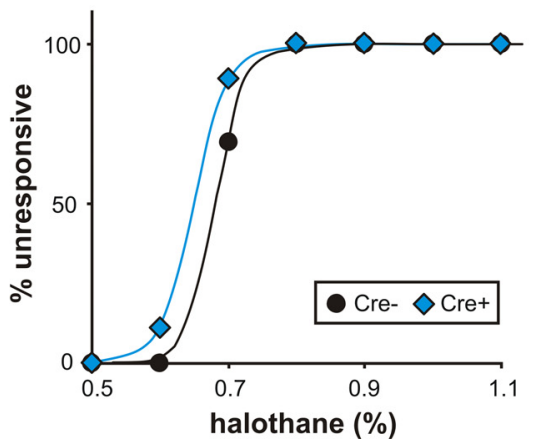

\section{isoflurane MAC}

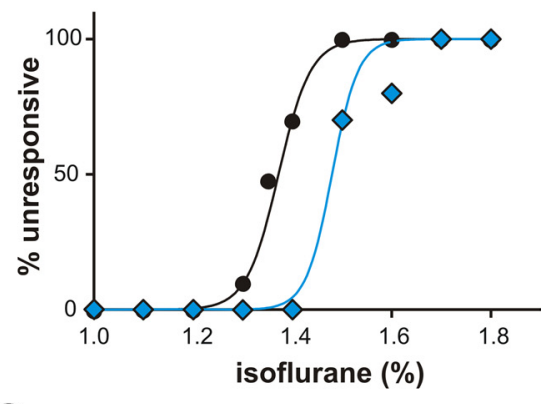

C

\section{halothane sedation}

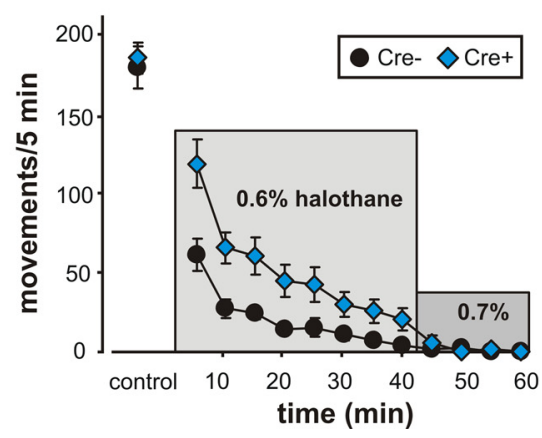

Figure 8. Effect of cholinergic-selective TASK channel deletion on hypnotic and sedative actions of halothane. $\boldsymbol{A}$, At incrementing concentrations of halothane ( $0.5-1.4 \%$, percentage inspired concentration) or isoflurane $(0.6-1.6 \%)$, the percentage of Cre control (filled circles) and (re ${ }^{+}$(filled diamonds) mice that failed to make a purposeful movement in response to a tail clamp was determined. The lines overlaid on data points represent best fits to logistic equations. $\boldsymbol{B}, \boldsymbol{A}$ loss-of-righting reflex assay was performed in Cre-negative (control) and Cre-positive TASK ${ }^{\mathrm{f} / \mathrm{f}}$ littermates at incrementing concentrations of halothane (0.5-1.1\%); overlaid lines represent best fits to logistic equations, with averages ( $\pm S E M$ ) of individual $E C_{50}$ values indicated on each plot. There was no difference in sensitivity of these animals to the hypnotic actions of halothane. $\boldsymbol{C}$, An assay of sedative halothane actions was performed in Cre-negative and Cre-positive mice. The halothane-induced decrease in activity was delayed in Cre-positive mice with TASK channel deletion in cholinergic neurons; these mice showed $\sim 2$-fold increase in total movements during the anesthesia exposure (see Results for details). This result was reminiscent of that seen with global knock-out of TASK channels.

control and ChAT-Cre-positive mice. As depicted in Figure $8 \mathrm{~A}$, higher concentrations of both anesthetics were required to immobilize the Cre-expressing mice in comparison with control animals (halothane: control, $1.00 \pm 0.02$ Cre $^{+}, 1.11 \pm 0.02 ; n=$ $8, p<0.0005$; isoflurane: control, $1.37 \pm 0.02$ Cre $^{+}, 1.50 \pm 0.03$; $n=10, p<0.005)$; indeed, the absolute MAC value and the relative shifts in sensitivity associated with the selective knockout were very close to those obtained when comparing C57BL/6J mice to global TASK knock-outs. These data indicate that TASK expression in cholinergic neurons, including motoneurons, accounts for most of the immobilizing actions of inhaled anesthetics mediated by TASK channels.

We found that global deletion of TASK channels also diminished sensitivity to hypnotic and sedative effects of halothane, but not isoflurane. Therefore, we examined whether these actions of halothane were also disrupted when TASK channels were deleted selectively in cholinergic neurons. As depicted in Figure $8 B$, the ability of halothane to induce LORR was not different in mice with or without expression of ChAT-Cre (Cre-negative, $0.68 \pm$ 0.01 ; Cre-positive, $0.65 \pm 0.02 ; n=13$ and 9, respectively). However, as shown in Figure $8 C$, we did observe a diminished sensitivity of Cre-expressing TASK- ${ }^{\mathrm{f} / \mathrm{f}}$ :TASK- $3{ }^{\mathrm{f} / \mathrm{f}}$ mice to the sedative effects of halothane. This was similar to the situation with global TASK channel knock-out mice insofar as the Cre-positive mice retained higher activity levels than their Cre-negative littermates during the anesthetic administration. In this case, there was a doubling of time spent active in Creexpressing animals (413.5 \pm 72.0 vs $168.5 \pm 28.8, n=11$ and 13 , respectively, $p<0.005)$. These data suggest that TASK channel modulation by halothane in cholinergic neurons contributes to the sedative properties of that anesthetic, but not to its hypnotic actions.

\section{Discussion}

In this work, we used multiple lines of knock-out mice to demonstrate directly that TASK channels account for a prominent motoneuronal $\mathrm{pH}$-sensitive background $\mathrm{K}^{+}$current that is activated by halothane and isoflurane. In addition, we showed that deletion of TASK-1 and/or TASK-3 in global knock-out mice is associated with decreased sensitivity to immobilizing actions of both those anesthetic compounds. A reduction in hypnotic and sedative effects of halothane, but not isoflurane, also reliably accompanied TASK channel ablation. There were no differences in immobilizing or hypnotic actions of etomidate between wild-type and TASK knock-out mice, which was consistent with the observation that this intravenous anesthetic compound does not modulate TASK channel activity and allayed concerns that differences in anesthetic sensitivity reflect some nonspecific effect of TASK channel deletion on neuronal excitability. Finally, we generated a novel line of mice in which both TASK-1 and TASK-3 were deleted selectively in cholinergic neurons. Importantly, we observed a reduction in sensitivity of these conditional TASK knock-outs to immobilizing actions of halothane and isoflurane that reproduced effects seen in the global knock-outs; these mice were also less sensitive to sedative effects of halothane. These results obtained with the conditional knock-outs suggest that TASK expression in cholinergic neurons is primarily responsible for the contributions of those channels to immobilizing and sedative anesthetic actions. In the case of immobilization, it is likely that anesthetic actions on TASK-expressing motoneurons play a role because (1) immobilization is mediated spinally and associated with decreased motoneuronal excitability (Kendig, 1993; Zhou et al., 1997; 1998; Rudolph and Antkowiak, 2004); and (2) motoneurons are the most likely cholinergic spinal cell group to participate in this reflex response.

\section{TASK channels contribute to anesthetic-induced immobilization}

The effect of deletion of an individual TASK channel on immobilizing actions of inhaled anesthetics has been explored in earlier broad phenotypic analyses of single subunit TASK-1 and TASK-3 knock-out mice (Linden et al., 2006; 2007; Pang et al., 2009). In those studies, a diminished sensitivity (i.e., higher MAC) was obtained in TASK-1 $1^{-1-}$ and TASK-3 $3^{-1-}$ mice only for halo- 
thane; immobilizing actions of isoflurane occurred at the same concentration in both TASK-1 and TASK-3 knock-outs (Linden et al., 2006; 2007). The reason for those earlier reports of agentselective effects on immobilization in TASK knock-out mice are not clear since, unlike rat TASK-1 (Berg et al., 2004), we find that isoflurane can activate the mouse variant of TASK-1, and our motoneuronal recordings demonstrate a decrease in both halothane- and isoflurane-activated currents in all TASK knockout mice. Thus, our behavioral data are in line with in vitro observations in that we find decreased sensitivity to immobilizing effects of both halothane and isoflurane in all three TASK knockout lines (TASK-1 ${ }^{-1-}$, TASK- $3^{-1-}$, and TASK ${ }^{-1-}$ ), whether on a congenic $\mathrm{C} 57 \mathrm{BL} / 6 \mathrm{~J}$ or a mixed genetic background.

It is important to point out that TASK channel deletion did not eliminate the immobilizing actions of either anesthetic (Linden et al., 2006; 2007); although the dose-response curve was shifted to the right, all animals still became immobilized at high anesthetic concentrations. These residual effects were seen even in double TASK knock-outs and must reflect actions on other anesthetic targets. One such molecular target may be the anesthetic-activated TREK-1 channels (Patel et al., 1999); a rightward shift in MAC sensitivity was observed in mice deleted for TREK-1 (Heurteaux et al., 2004), possibly reflecting removal of an "excitability brake" provided by TREK-1 channels in sensory nociceptors (Alloui et al., 2006). It is also interesting that TASK knock-out mice have increased sensitivity to $\mathrm{GABA}_{\mathrm{A}}$ ligands (Linden et al., 2008), and because $\mathrm{GABA}_{\mathrm{A}}$ receptors are well known anesthetic targets (Rudolph and Antkowiak, 2004; Grasshoff et al., 2005; Franks, 2008), enhanced effects of anesthetics on $\mathrm{GABA}_{\mathrm{A}}$ receptors could compensate for the loss of TASK channels in behavioral assays of anesthetic sensitivity. If this is the case, it likely involves neuronal targets other than motoneurons, since we observed only small $\mathrm{GABA}_{\mathrm{A}}$-mediated anesthetic effects in motoneurons, with no differences between wild-type and TASK knock-out mice.

\section{Motoneurons are the most likely site for TASK channel contributions to anesthetic-induced immobilization}

Our previous work with motoneurons (Sirois et al., 1998, 2000), coupled with the obvious contributions of those cells to motor reflexes, led us to focus on this cell group as a possible site of action for immobilizing anesthetic actions mediated by TASK channels. To examine this, we used ChAT-driven Cre expression to limit TASK gene excision to cholinergic neurons, including motoneurons. Deletion of TASK channels in those specific cell groups fully recapitulated effects on immobilization of a complete TASK knock-out. The obvious shortcoming in this particular mouse model is that motoneurons are not the only cholinergic neurons that express TASK channels (Talley et al., 2001; Karschin et al., 2001; Berg and Bayliss, 2007). Unfortunately, TASK gene deletion was not sufficiently restricted or penetrant in four additional lines of mice expected to produce a more motoneuron-selective Cre expression pattern. In any case, although our use of the ChAT-Cre mice does not allow us to formally rule out a contribution from other groups of cholinergic neurons (e.g., striatal interneurons, basal forebrain cell groups, sympathetic preganglionic neurons), we do not favor a role for these other cell groups since either they are not present in the spinal cord, where anesthetic-induced immobilization is mediated (Kendig, 1993; Rudolph and Antkowiak, 2004), or they have no obvious link to motor reflex action.

There was not a strict correlation between effects of TASK channel deletion on motoneuronal currents in vitro and anes- thetic sensitivity in vivo. Specifically, we found similar shifts in MAC with single subunit and double TASK $^{-1-}$ knock-out mice even though cellular responses to anesthetics were more strongly diminished in double TASK ${ }^{-1-}$ mice. We suggest that this reflects a limit to the contribution of motoneuronal TASK channels to the overall behavioral response and a role for other anesthetic targets in determining anesthetic sensitivity. This view is supported by previous observations that TREK-1 channels also make a contribution to immobilization by various inhalational anesthetics; for halothane, the effect of TREK-1 deletion on MAC was even greater than we found here for TASK deletion (from 0.89 to $1.32 \%$ ) (Heurteaux et al., 2004). It is also consistent with the observation that immobilization is ultimately obtained in TASK knock-out mice, even if at a higher anesthetic concentration.

\section{Motoneuronal background $\mathrm{K}^{+}$current is mediated by TASK channels}

Our previous work in rat motoneurons implicated TASK channels based on shared properties of the native motoneuronal current and recombinant TASK currents (i.e., similar voltagedependent and kinetic properties) (Sirois et al., 2000; 2002; Talley et al., 2000; Berg et al., 2004). Although attribution of native currents to TASK channels based on such shared properties has been validated in knock-out mice for a number of other central neurons (e.g., raphe, cerebellar granule, thalamocortical) (Aller et al., 2005; Meuth et al., 2006; Brickley et al., 2007; Mulkey et al., 2007), that was not the case for glucose-activated $\mathrm{K}^{+}$currents initially identified as TASK-like in orexin neurons (Burdakov et al., 2006; Gonzalez et al., 2009; Guyon et al., 2009). In this work, we demonstrate unequivocally that TASK channels are responsible for the $\mathrm{pH}$ - and anesthetic-sensitive background $\mathrm{K}^{+}$current in mouse motoneurons. It is also worth noting that our earlier work suggested a substantial component of motoneuronal TASK-like current is due to heteromeric channels (Berg et al., 2004), a result supported here by the finding that the combined decrease in TASK-like current in motoneurons with deletion of TASK -1 and TASK-3 individually was $>100 \%$ of the total TASK current defined by deletion of both subunits simultaneously. Combined with elegant single channel work (Kang et al., 2004; Kim et al., 2009) and evidence from other TASK knock-out mice (Aller et al., 2005), it seems clear that heteromeric conformations of TASK-1 and TASK-3 should be anticipated in sites of coexpression.

\section{TASK channels contribute to sedative and hypnotic effects of halothane}

We found a consistent difference in hypnotic and sedative effects of halothane, but not isoflurane, in single subunit and double TASK- $1^{-1-}$ :TASK- $3^{-1-}$ knock-out mice whether we examined mouse strains on a C57BL/6J or on a mixed genetic background. These data do not agree with results reported for a different mixed genetic line of TASK-1 knock-out mice, for which hypnotic sensitivity to isoflurane was slightly diminished but halothane sensitivity was unchanged (Linden et al., 2006). The reasons for opposite results from these two independently generated lines of TASK-1 knock-out mice remain unclear. However, similar to our results, a more recent paper with a TASK-3 knockout mouse line reported a decrease in sensitivity to hypnotic effects of halothane as well as altered sleep structure (Pang et al., 2009). Interestingly, a prominent difference in TASK-3 knockouts was a slower transition from wake to sleep periods (Pang et al., 2009) that is reminiscent of the delayed halothane-induced sedation we observed in TASK knock-out mice. In that other 
work, disrupted halothane-activated theta rhythms were implicated and, because theta activation was sensitive to atropine, disruption of anesthetic action was proposed to involve TASK channel interactions with cholinergic signaling (Pang et al., 2009). In this respect, it is intriguing that we found diminished sensitivity to sedating actions of halothane in mice with TASK channel deletion restricted to cholinergic neurons. Since hypnotic sensitivity was unaffected in the conditional knock-outs, it appears that TASK contributions to halothane-induced hypnosis involve noncholinergic TASK-expressing cell neurons (e.g., aminergic, thalamocortical) (Sirois et al., 2000; Washburn et al., 2002; Meuth et al., 2003; 2006).

In conclusion, this work provides strong evidence that TASK channel activation in motoneurons contributes to immobilizing effects of inhaled anesthetics; insofar as the drugs remained capable of causing immobility in these knock-out mice, albeit at higher concentrations, the work also supports the idea that additional molecular and neuronal targets contribute to this important anesthetic action. Similar studies with new cell type-specific knock-out or knock-in mouse models will be required to validate other candidate anesthetic targets and localize their central sites of action.

\section{References}

Aghajanian GK, Rasmussen K (1989) Intracellular studies in the facial nucleus illustrating a simple new method for obtaining viable motoneurons in adult rat brain slices. Synapse 3:331-338.

Aller MI, Veale EL, Linden AM, Sandu C, Schwaninger M, Evans LJ, Korpi ER, Mathie A, Wisden W, Brickley SG (2005) Modifying the subunit composition of TASK channels alters the modulation of a leak conductance in cerebellar granule neurons. J Neurosci 25:11455-11467.

Alloui A, Zimmermann K, Mamet J, Duprat F, Noel J, Chemin J, Guy N, Blondeau N, Voilley N, Rubat-Coudert C, Borsotto M, Romey G, Heurteaux C, Reeh P, Eschalier A, Lazdunski M (2006) TREK-1, a K ${ }^{+}$channel involved in polymodal pain perception. EMBO J 25:2368-2376.

Berg AP, Bayliss DA (2007) Striatal cholinergic interneurons express a receptor-insensitive homomeric TASK-3-like background $\mathrm{K}^{+}$current. J Neurophysiol 97:1546-1552.

Berg AP, Talley EM, Manger JP, Bayliss DA (2004) Motoneurons express heteromeric TWIK-related acid-sensitive $\mathrm{K}^{+}$(TASK) channels containing TASK-1 (KCNK3) and TASK-3 (KCNK9) subunits. J Neurosci 24:6693-6702.

Brickley SG, Aller MI, Sandu C, Veale EL, Alder FG, Sambi H, Mathie A, Wisden W (2007) TASK-3 two-pore domain potassium channels enable sustained high-frequency firing in cerebellar granule neurons. J Neurosci 27:9329-9340.

Burdakov D, Jensen LT, Alexopoulos H, Williams RH, Fearon IM, O'Kelly I, Gerasimenko O, Fugger L, Verkhratsky A (2006) Tandem-pore $\mathrm{K}^{+}$ channels mediate inhibition of orexin neurons by glucose. Neuron 50:711-722.

Davies LA, Hu C, Guagliardo NA, Sen N, Chen X, Talley EM, Carey RM, Bayliss DA, Barrett PQ (2008) TASK channel deletion in mice causes primary hyperaldosteronism. Proc Natl Acad Sci U S A 105:2203-2208.

Eger EI, Saidman LJ, Brandstater B (1965) Minimum alveolar anesthetic concentration: a standard of anesthetic potency. Anesthesiology 26:756-763.

Franks NP (2008) General anaesthesia: from molecular targets to neuronal pathways of sleep and arousal. Nat Rev Neurosci 9:370-386.

Franks NP, Lieb WR (1988) Volatile general anaesthetics activate a novel neuronal $\mathrm{K}^{+}$current. Nature 333:662-664.

Garfield JM, Bukusoglu C (1996) Propofol and ethanol produce additive hypnotic and anesthetic effects in the mouse. Anesth Analg 83:156-161.

Gong S, Doughty M, Harbaugh CR, Cummins A, Hatten ME, Heintz N, Gerfen CR (2007) Targeting Cre recombinase to specific neuron populations with bacterial artificial chromosome constructs. J Neurosci 27:9817-9823.

Gonzalez JA, Jensen LT, Doyle SE, Miranda-Anaya M, Menaker M, Fugger L, Bayliss DA, Burdakov D (2009) Deletion of TASK1 and TASK3 channels disrupts intrinsic excitability but does not abolish glucose or $\mathrm{pH}$ responses of orexin/hypocretin neurons. Eur J Neurosci 30:57-64.

Grasshoff C, Rudolph U, Antkowiak B (2005) Molecular and systemic mechanisms of general anaesthesia: the 'multi-site and multiple mechanisms' concept. Curr Opin Anaesthesiol 18:386-391.

Guyon A, Tardy MP, Rovere C, Nahon JL, Barhanin J, Lesage F (2009) Glucose inhibition persists in hypothalamic neurons lacking tandem-pore $\mathrm{K}^{+}$channels. J Neurosci 29:2528-2533.

Heurteaux C, Guy N, Laigle C, Blondeau N, Duprat F, Mazzuca M, LangLazdunski L, Widmann C, Zanzouri M, Romey G, Lazdunski M (2004) TREK-1, a K ${ }^{+}$channel involved in neuroprotection and general anesthesia. EMBO J 23:2684-2695.

Jurd R, Arras M, Lambert S, Drexler B, Siegwart R, Crestani F, Zaugg M, Vogt KE, Ledermann B, Antkowiak B, Rudolph U (2003) General anesthetic actions in vivo strongly attenuated by a point mutation in the $\mathrm{GABA}_{\mathrm{A}}$ receptor $\beta 3$ subunit. FASEB J 17:250-252.

Kang D, Han J, Talley EM, Bayliss DA, Kim D (2004) Functional expression of TASK-1/TASK-3 heteromers in cerebellar granule cells. J Physiol 554:64-77.

Karschin C, Wischmeyer E, Preisig-Muller R, Rajan S, Derst C, Grzeschik KH, Daut J, Karschin A (2001) Expression pattern in brain of TASK-1, TASK-3, and a tandem pore domain $\mathrm{K}^{+}$channel subunit, TASK-5, associated with the central auditory nervous system. Mol Cell Neurosci 18:632-648.

Kendig JJ (1993) Spinal cord as a site of anesthetic action. Anesthesiology 79:1161-1162.

Kim D, Cavanaugh EJ, Kim I, Carroll JL (2009) Heteromeric TASK-1/ TASK-3 is the major oxygen-sensitive background $\mathrm{K}^{+}$channel in rat carotid body glomus cells. J Physiol 587:2963-2975.

Linden AM, Aller MI, Leppa E, Vekovischeva O, Aitta-Aho T, Veale EL, Mathie A, Rosenberg P, Wisden W, Korpi ER (2006) The in vivo contributions of TASK-1-containing channels to the actions of inhalation anesthetics, the $\alpha 2$ adrenergic sedative dexmedetomidine, and cannabinoid agonists. J Pharmacol Exp Ther 317:615-626.

Linden AM, Sandu C, Aller MI, Vekovischeva OY, Rosenberg PH, Wisden W, Korpi ER (2007) TASK-3 knock-out mice exhibit exaggerated nocturnal activity, impairments in cognitive functions, and reduced sensitivity to inhalation anesthetics. J Pharmacol Exp Ther 323:924-934.

Linden AM, Aller MI, Leppa E, Rosenberg PH, Wisden W, Korpi ER (2008) $\mathrm{K}^{+}$channel TASK-1 knockout mice show enhanced sensitivities to ataxic and hypnotic effects of $\mathrm{GABA}_{\mathrm{A}}$ receptor ligands. J Pharmacol Exp Ther 327:277-286.

Lu QR, Sun T, Zhu Z, Ma N, Garcia M, Stiles CD, Rowitch DH (2002) Common developmental requirement for Olig function indicates a motor neuron/oligodendrocyte connection. Cell 109:75-86.

Meuth SG, Budde T, Kanyshkova T, Broicher T, Munsch T, Pape HC (2003) Contribution of TWIK-related acid-sensitive $\mathrm{K}^{+}$channel 1 (TASK1) and TASK3 channels to the control of activity modes in thalamocortical neurons. J Neurosci 23:6460-6469.

Meuth SG, Aller MI, Munsch T, Schuhmacher T, Seidenbecher T, Meuth P, Kleinschnitz C, Pape HC, Wiendl H, Wisden W, Budde T (2006) The contribution of TWIK-related acid-sensitive $\mathrm{K}^{+}$-containing channels to the function of dorsal lateral geniculate thalamocortical relay neurons. Mol Pharmacol 69:1468-1476.

Mulkey DK, Talley EM, Stornetta RL, Siegel AR, West GH, Chen X, Sen N, Mistry AM, Guyenet PG, Bayliss DA (2007) TASK channels determine $\mathrm{pH}$ sensitivity in select respiratory neurons but do not contribute to central respiratory chemosensitivity. J Neurosci 27:14049-14058.

Nicoll RA, Madison DV (1982) General anesthetics hyperpolarize neurons in the vertebrate central nervous system. Science 217:1055-1057.

Pang DS, Robledo CJ, Carr DR, Gent TC, Vyssotski AL, Caley A, Zecharia AY, Wisden W, Brickley SG, Franks NP (2009) An unexpected role for TASK-3 potassium channels in network oscillations with implications for sleep mechanisms and anesthetic action. Proc Natl Acad Sci U S A 106:17546-17551.

Patel AJ, Honoré E, Lesage F, Fink M, Romey G, Lazdunski M (1999) Inhalational anesthetics activate two-pore-domain background $\mathrm{K}^{+}$channels. Nat Neurosci 2:422-426.

Quinlan JJ, Homanics GE, Firestone LL (1998) Anesthesia sensitivity in mice that lack the $\beta 3$ subunit of the gamma-aminobutyric acid type A receptor. Anesthesiology 88:775-780.

Reynolds DS, Rosahl TW, Cirone J, O’Meara GF, Haythornthwaite A, 
Newman RJ, Myers J, Sur C, Howell O, Rutter AR, Atack J, Macaulay AJ, Hadingham KL, Hutson PH, Belelli D, Lambert JJ, Dawson GR, McKernan R, Whiting PJ, Wafford KA (2003) Sedation and anesthesia mediated by distinct $\mathrm{GABA}_{\mathrm{A}}$ receptor isoforms. J Neurosci 23:8608-8617.

Rudolph U, Antkowiak B (2004) Molecular and neuronal substrates for general anaesthetics. Nat Rev Neurosci 5:709-720.

Sirois JE, Pancrazio JJ, Lynch C III, Bayliss DA (1998) Multiple ionic mechanisms mediate inhibition of rat motoneurones by inhalation anaesthetics. J Physiol 512:851-862.

Sirois JE, Lei Q, Talley EM, Lynch C III, Bayliss DA (2000) The TASK-1 two-pore domain $\mathrm{K}^{+}$channel is a molecular substrate for neuronal effects of inhalation anesthetics. J Neurosci 20:6347-6354.

Sirois JE, Lynch C, III, Bayliss DA (2002) Convergent and reciprocal modulation of a leak $\mathrm{K}^{+}$current and $\mathrm{I}_{\mathrm{h}}$ by an inhalational anaesthetic and neurotransmitters in rat brainstem motoneurones. J Physiol 541:717729.

Srinivas S, Watanabe T, Lin CS, William CM, Tanabe Y, Jessell TM, Costan- tini F (2001) Cre reporter strains produced by targeted insertion of EYFP and ECFP into the ROSA26 locus. BMC Dev Biol 1:4.

Talley EM, Lei Q, Sirois JE, Bayliss DA (2000) TASK-1, a two-pore domain $\mathrm{K}^{+}$channel, is modulated by multiple neurotransmitters in motoneurons. Neuron 25:399-410.

Talley EM, Solorzano G, Lei Q, Kim D, Bayliss DA (2001) CNS distribution of members of the two-pore-domain (KCNK) potassium channel family. J Neurosci 21:7491-7505.

Washburn CP, Sirois JE, Talley EM, Guyenet PG, Bayliss DA (2002) Serotonergic raphe neurons express TASK channel transcripts and a TASK-like $\mathrm{pH}-$ and halothane-sensitive $\mathrm{K}^{+}$conductance. J Neurosci 22:1256-1265.

Zhou HH, Mehta M, Leis AA (1997) Spinal cord motoneuron excitability during isoflurane and nitrous oxide anesthesia. Anesthesiology 86:302-307.

Zhou HH, Jin TT, Qin B, Turndorf H (1998) Suppression of spinal cord motoneuron excitability correlates with surgical immobility during isoflurane anesthesia. Anesthesiology 88:955-961. 